\title{
The Application of Differential Scanning Calorimetry to Investigate Precipitation Behavior in Nickel-Base Superalloys Under Continuous Cooling and Heating Conditions
}

\author{
S.L. SEMIATIN, N.C. LEVKULICH, R. LARSEN, J.S. TILEY, K.N. WERTZ, \\ F. ZHANG, T.M. SMITH, R.Y. ZHANG, H.B. DONG, P. GADAUD, and J. CORMIER
}

\begin{abstract}
A suite of experimental tools and fast-acting, numerical-simulation techniques was used to quantify the precipitation behavior of three nickel-base superalloys: IN-100, LSHR, and 718. Experimental methods comprised differential scanning calorimetry (DSC) to establish the specific heat as a function of temperature and selected direct-resistance heating trials (using a Gleeble ${ }^{\circledR}$ machine) to obtain samples for microstructural analysis. For the DSC experiments, each alloy was cooled at a prescribed constant rate (between 5 and $20 \mathrm{~K} / \mathrm{min}$ ) after an initial soak/equilibration in the high-temperature, single-phase (supersolvus) temperature regime. On-heating DSC trials beginning at ambient temperature were also performed on alloy 718 in three different starting conditions: super- $\delta$-solvus solution treated and water quenched (denoted as ST), solution treated and aged (STA), and solution treated and overaged (STOA). DSC results, revealing the thermal signatures associated with the kinetics of precipitation of $\gamma^{\prime}$ (IN-100, LSHR) or $\gamma^{\prime}$ and $\gamma^{\prime \prime}$ (718), were interpreted using a previously-developed fast-acting routine that treats concurrent nucleation, growth, coarsening, and dissolution. For these simulations, special attention was paid to various thermo-kinetic input parameters including equilibrium solvus-approach curves, bulk free energies of transformation, matrix-precipitate interface energies, and effective diffusivities. For the $\gamma-\gamma^{\prime}$ superalloys (IN-100 and LSHR), estimates of precipitate volume fraction as a function of temperature from the specific-heat data revealed semi-quantitative agreement with simulation predictions. For the $\gamma-\gamma^{\prime}-\gamma^{\prime \prime}$ superalloy (718), simulation predictions of precipitate volume fractions were converted to specific heat as a function of temperature and showed semi-quantitative agreement with the direct measurements.
\end{abstract}

https://doi.org/10.1007/s11661-021-06362-x

(C) The Minerals, Metals \& Materials Society and ASM International 2021

S.L. SEMIATIN and K.N. WERTZ are with the Air Force Research Laboratory, Materials and Manufacturing Directorate, Wright-Patterson Air Force Base, Dayton, OH 45433. Contact e-mail: sheldon.semiatin.1@us.af.mil N.C. LEVKULICH is with UES, Inc., Dayton, OH 45432. R. LARSEN is with the Thermophysical Properties Research Laboratory, Inc., West Lafayette, IN 47906. J.S. TILEY is with the Oak Ridge National Laboratory, Oak Ridge, TN 37830. F. ZHANG is with CompuTherm LLC, Middleton, WI, 53562. T.M. SMITH is with NASA Glenn Research Center, Cleveland, OH, 44135. R.Y. ZHANG is with The Open University, Milton Keynes, MK7 6AA, UK. H.B. DONG is with the University of Leicester, Leicester, LE1 7RH, UK. P. GADAUD, and J. CORMIER are with Institut Pprime, UPR CNRS 3346, ISAE-ENSMA, 1 Avenue Clément Ader, BP 40109, 86961 Futuroscope- Chasseneuil Cedex, France.

Manuscript submitted February 12, 2021; accepted May 31, 2021.

Article published online July 19, 2021

\section{INTRODUCTION}

NiCKEL-BASE superalloys are enabling materials for structural applications requiring high strength and resistance to creep, fatigue, and oxidation at elevated service temperatures. These attributes are obtained by the control of solid-solution strengthening, grain size, precipitate volume fraction, size, and morphology, etc. and are thus greatly influenced by alloy design, synthesis, and manufacture. ${ }^{[1,2]}$ In particular, alloying-element type and magnitude often dictate the synthesis and subsequent processing approach. For example, superalloys with low-to-moderate levels of alloying (such as Hastelloy X, 625, 718, and Waspaloy) can be melted and cast into ingots having minimal macro-segregation and quench-crack sensitivity. Using methods such as open or closed-die forging, radial forging, ring rolling, etc., ingots are subsequently hot worked to obtain wrought semi-finished products or shaped components with a 
recrystallized grain structure. With increasing alloy content, on the other hand, synthesis is often performed via powder metallurgy (PM) or solidification techniques. Powder production and consolidation (usually via blind-die compaction and extrusion) provide a billet product that is superplastic and can therefore be isothermally forged into a complex shape. For the most highly-alloyed materials, casting techniques that result in an equiaxed, directionally-solidified, or single-crystal microstructure are often utilized. ${ }^{[3]}$

The final processing step in the manufacture of nickel-base-superalloy parts via ingot- or powder- metallurgy techniques often consists of solution treatment and aging to develop a desirable precipitate distribution. For wrought materials, aging following solution treatment and quenching is frequently performed isothermally in a single or two-step process. For 718, for instance, aging is usually done at $993 \mathrm{~K}$ (primarily for the precipitation of $\gamma^{\prime \prime}$ ) and then at $893 \mathrm{~K}$ (for $\gamma^{\prime}$ ). Alternatively, the heat treatment of 718 sometimes comprises solution treatment followed by controlled cooling through the aging regime or by a direct-aging method. ${ }^{[4]}$ The latter approach involves high temperature preheating and hot working in place of a conventional solution-treatment process per se and gives rise to higher strength levels. Depending on the final application, PM superalloys strengthened by $\gamma^{\prime}$ are solution treated above or below the solvus and then controlled cooled to produce secondary $\gamma^{\prime}$ (at relatively high temperatures) and then very-fine tertiary $\gamma^{\prime}$ at lower temperatures. Additional tertiary $\gamma^{\prime}$ may then be developed by isothermal aging at a moderately-low temperature above the expected service temperature.

Because of the importance in controlling the size and volume fraction of precipitates in superalloys, extensive experimental and modeling work has been conducted to quantify aging response. Empirical approaches typically have consisted of the development of cooling-transformation or isothermal-transformation diagrams (e.g., References 5-10 for 718) or phenomenological relations between precipitate size and cooling rate for PM $\gamma-\gamma^{\prime}$ superalloys. ${ }^{[11-18]}$ Because of the very fine sizes of the precipitates (typically between 10 and $500 \mathrm{~nm}$ ), however, experimental characterization based on metallographic observations can be prone to substantial measurement error and uncertainty. For this reason, other (non-destructive) techniques such as those based on electrical resistivity, differential thermal analysis (DTA), "single-sensor" DTA, ultrasonic/modulus measurements, and neutron/X-ray diffraction have been applied to obtain qualitative and sometimes quantitative results. ${ }^{[19-23]}$

Experimental challenges in the determination of precipitation behavior in nickel-base superalloys can also be mitigated using modeling-and-simulation techniques, provided the assumed physical basis underlying microstructure evolution (e.g., nucleation, growth, and coarsening) is sound and the material properties required for numerical calculations are known accurately. Modeling techniques fall into two main categories, mean field and phase field. In mean-field approaches, ${ }^{[24-38]}$ the composition of the matrix is assumed to be uniform (except at and near the matrix-precipitate interface), and precipitation is often treated using descriptions of homogeneous (and sometimes heterogeneous) nucleation, diffusional growth, and coarsening. Formulations based on the phase-field technique $e^{[39-41]}$ are similar except local variations in composition and the concomitant variations in nucleation and growth behavior are taken into account.

The work reported here was part of ongoing efforts $^{[16,18,23,29,38]}$ to develop novel test methods and fast-acting simulation tools to quantify precipitation behavior in nickel-base superalloys. In the present research, the focus was on behavior under continuous cooling and heating conditions for both wrought and PM superalloys. The specific objectives were twofold: (i) To establish the feasibility of using differential scanning calorimetry (DSC) to interrogate precipitation behavior in a quantitative fashion and (ii) to use this experimental technique to provide guidance for the refinement of fast-acting simulations and associated input data, especially for complex alloys with two precipitating phases. To meet these needs, DSC experiments and parallel fast-acting precipitation simulations were performed for two $\gamma-\gamma^{\prime}$ alloys (IN-100 and LSHR) and alloy 718 whose principal strengthening phases comprise both $\gamma^{\prime \prime}$ and $\gamma^{\prime}$. The present work on 718 also included efforts to provide further insight into the values of the material coefficients which play an important role in precipitation simulations for this material.

\section{MATERIALS AND PROCEDURES}

Differential scanning calorimetry and fast-acting, mean-field simulations were performed for three different superalloys to establish and refine tools for quantifying precipitation behavior under continuous cooling and heating conditions.

\section{A. Materials}

Three nickel-base alloys, IN-100, LSHR (denoting "low-solvus, high refractory" alloy, developed by $\mathrm{NASA}^{[42,43]}$ ), and 718 were used in this work. The specific heat as a function of temperature was determined for the PM alloys IN-100 and LSHR ${ }^{[44,45]}$ in 2015 and 2003, respectively, but not analyzed/interpreted further. Their behavior during DSC provided useful insights prior to the effort for the more complex alloy 718.

The IN-100 program material had been received from Pratt \& Whitney as 89 -mm-diameter bar that had been extracted from the center of a larger-diameter extruded billet. ${ }^{[46]}$ It had a measured composition (in weight percent) of $18.5 \mathrm{Co}, 12.4 \mathrm{Cr}, 5.0 \mathrm{Al}, 4.3 \mathrm{Ti}, 3.2 \mathrm{Mo}, 0.8$ $\mathrm{V}, 0.07 \mathrm{C}, 0.02 \mathrm{~B}, 0.06 \mathrm{Zr}$, balance $\mathrm{Ni}$, and $\gamma^{\prime}$ solvus temperature $\left(T_{\gamma^{\prime}}\right)$ of $1458 \mathrm{~K}$. Prior to DSC analysis, the material had been supersolvus solution treated at 1477 $\mathrm{K}$ for 1 hour and air cooled, thereby producing a dispersion of $\sim 700 \mathrm{~nm}$ cuboidal $\gamma^{\prime}$ precipitates, a number of which had undergone splitting (Figure 1(a)), and a $\gamma$ grain size of $\sim 25 \mu \mathrm{m}$. 

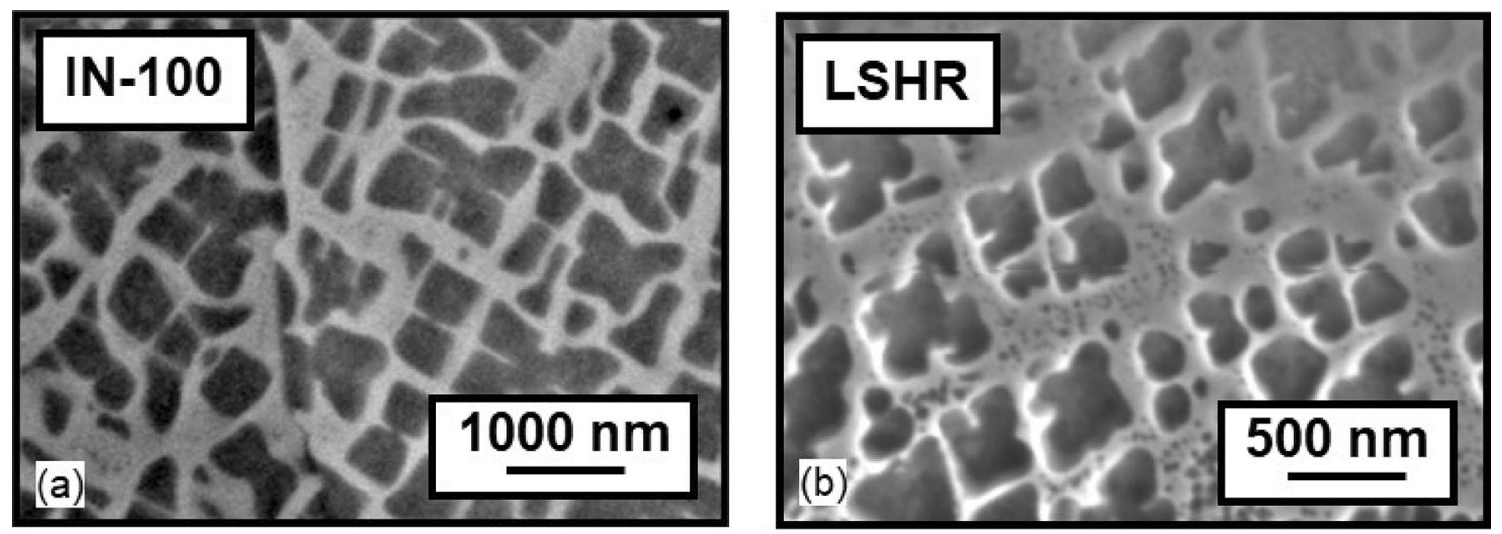

Fig. 1-Backscattered-electron (BSE) images of (a) IN-100 and (b) LSHR ${ }^{[43]}$ prior to DSC.

The LSHR material had a measured composition (in weight percent) of $20.7 \mathrm{Co}, 12.5 \mathrm{Cr}, 3.46 \mathrm{Al}, 3.50 \mathrm{Ti}$, $2.73 \mathrm{Mo}, 4.33 \mathrm{~W}, 1.45 \mathrm{Nb}, 1.60 \mathrm{Ta}, 0.029 \mathrm{C}, 0.028 \mathrm{~B}$, $0.049 \mathrm{Zr}$, balance $\mathrm{Ni}$ and a $T_{\gamma^{\prime}}$ of $1430 \mathrm{~K} \cdot{ }^{[43]}$ It had been extruded, isothermally forged, supersolvus solution treated (at $1444 \mathrm{~K}$ ), fan cooled, and finally aged $8 \mathrm{~h}$ at $1089 \mathrm{~K}$ to produce a microstructure comprising $\sim 33-\mu \mathrm{m}$ $\gamma$ grains, $\sim 200-\mathrm{nm}$ secondary $\gamma^{\prime}$ precipitates, and $\sim$ 35-nm tertiary $\gamma^{\prime}$ precipitates (Figure 1(b)).$^{[43]}$

The alloy 718 material was received as $2-\mathrm{mm}$ thick hot-rolled sheet which had been finished by continuous annealing using proprietary parameters; its composition (in weight percent) was $17.6 \mathrm{Cr}, 19.27 \mathrm{Fe}, 4.93 \mathrm{Nb}, 0.54$ $\mathrm{Al}, 0.98 \mathrm{Ti}, 3.01 \mathrm{Mo}, 0.55 \mathrm{Co}, 0.06 \mathrm{C}$, balance Ni. In the as-received (AR) condition, the microstructure consisted of $\gamma$ grains with an average circle-equivalent diameter (CED) of $\sim 20 \mu \mathrm{m}$ and widely-dispersed carbides $\sim 2$ to 4 $\mu \mathrm{m}$ in diameter (Figure 2(a)) At a magnification of 200,000 times, there were no discernable $\gamma^{\prime \prime}, \gamma^{\prime}$, or $\delta$ phase precipitates.

In the present experimental program, the 718 alloy was used in four different conditions: as-received, super- $\delta$-solvus solution treated (ST), ST + aged (STA), and ST + overaged (STOA). The super- $\delta$-solvus solution treatment comprised 1 hour at $1339 \mathrm{~K}$ followed by water quenching. After the ST treatment, the Vickers hardness (Hv) using a load of $1000 \mathrm{~g}$ was determined to be $203.6 \pm 7.4$, a value comparable to that reported previously in the literature for fully-solutioned material. ${ }^{[47]}$ The AR material exhibited a similar Hv $(213.1 \pm$ 8.6), thus suggesting that the mill processing used in its manufacture had likely also produced a fully-solutioned condition.

The aging treatment for the STA 718 samples consisted of 8 hours at $993 \mathrm{~K}$ plus 8 hours at $893 \mathrm{~K}$ followed by air cooling. The STOA treatment was similar except that the time at each temperature was increased from 8 to 24 hours. The super- $\delta$-solvus solution treatment gave rise to a $\gamma$ grain size of $\sim 75$ $\mu \mathrm{m}$ (Figures 2(b), (d)); aging produced distributions of disk-like/ellipsoidal $\gamma^{\prime \prime}$ and spheroidal $\gamma^{\prime}$ precipitates with a total volume fraction of 0.153 and CED of $10.8 \mathrm{~nm}$ (STA) or $15.9 \mathrm{~nm}$ (STOA) (Figures 2(c), (e)). Although no attempt was made to estimate the discrete area fractions or sizes of each of the two different types of precipitates, the oblate nature of $\gamma^{\prime \prime}$ was barely obvious in the STA samples (Figure 2(c)), but became more noticeable for a number of the precipitates in the STOA condition (Figure 2(e)). This broad trend of decreasing aspect ratio (i.e., length of the minor to major axis lengths) of $\gamma^{\prime \prime}$ particles with increasing size was in agreement with prior observations. ${ }^{[36,48]}$

\section{B. Experimental Procedures}

DSC, direct-resistance heat treatments, and furnace heat treatments were performed to quantify precipitation behavior and establish input data for precipitation simulations.

DSC was performed at the Thermophysical Properties Research Laboratory (TPRL) on IN-100, LSHR, and 718 with the ST, STA, or STOA microstructures. For this purpose, small disks measuring $5.8-\mathrm{mm}$ diameter $\times$ $1.5-\mathrm{mm}$ thickness were extracted via a combination of electrical-discharge machining and grinding operations. Each DSC trial was performed in an argon atmosphere using a constant cooling/heating rate of $15 \mathrm{~K} / \mathrm{min}$ (IN-100, LSHR) or 5,10 , or $20 \mathrm{~K} / \mathrm{min}$ (718). The experiments were performed over a temperature range between $296 \mathrm{~K}$ and $\sim 20 \mathrm{~K}$ above the respective $\gamma^{\prime}$ solvus (IN-100, LSHR) or $\delta$ solvus (718) using a Netzsch Model 404 differential scanning calorimeter. During DSC, the differential temperature between a test sample and reference head is measured and converted into a heat flow $(\mathrm{mW})$. Runs using a blank sample, sapphire sample, and the test sample are performed to obtain heat flows from each procedure. The specific heat is then calculated based on the known sapphire and test sample weights, the specific heat values of the sapphire, and the ratio of the sapphire to baseline and test sample to baseline behaviors at given temperatures. ${ }^{[49,50]}$

Because samples cannot be quenched at intermediate temperatures during DSC (and thus enable microstructure determination), selected heating/cooling experiments for 718 in the ST condition were preformed using a Gleeble ${ }^{\circledR}$ 3800-499 thermal-mechanical test system (manufactured by Dynamic Systems, Inc. (DSI), Poestenkill, NY). For these runs, strips 

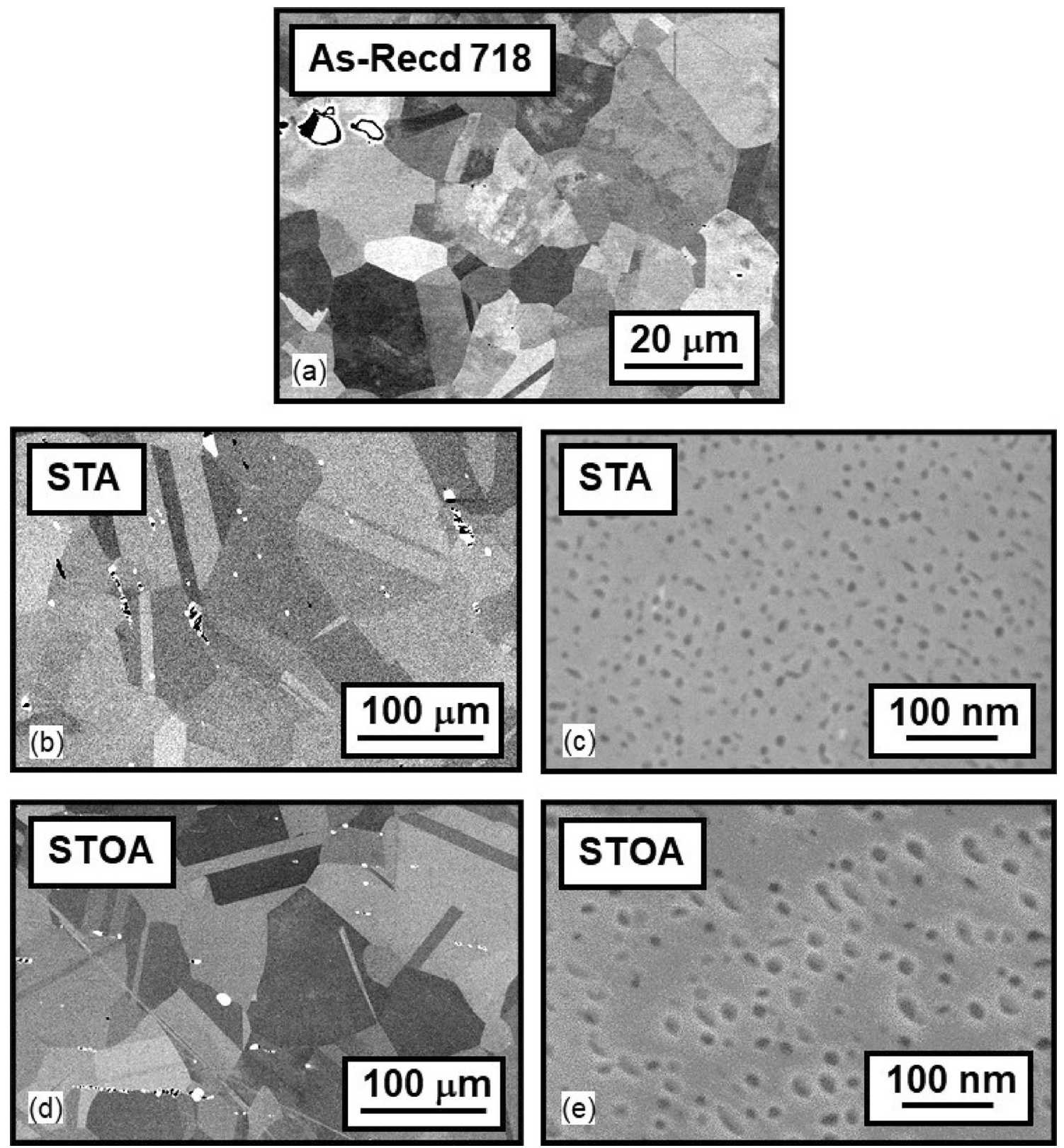

Fig. 2-Alloy 718 microstructures: (a) As-received condition or those developed via heat treatments comprising $(b, c)$ super- $\delta$-solvus solution treatment, water quenching, and aging (STA) or $(d, e)$ super- $\delta$-solvus solution treatment, water quenching, and overaging (STOA). Imaging methods were (a, b, d) BSE or (c, e) SE.

measuring 12.7-mm width $\times 115$-mm length $\times 1.5 \mathrm{~mm}$ thickness were resistance heated/cooled in vacuum at a rate of $5 \mathrm{~K} / \mathrm{min}$ and then water quenched at a prescribed temperature. For on-cooling experiments, test samples were heated first to $1373 \mathrm{~K}$, soaked 15 minutes, cooled, and quenched immediately upon reaching $993 \mathrm{~K}$ or 773 $\mathrm{K}$. The on-heating trials consisted of heating to $1073 \mathrm{~K}$ or $1173 \mathrm{~K}$ and then water quenching.

A number of furnace heat treatments at temperatures between $973 \mathrm{~K}$ and $1200 \mathrm{~K}$ and times between 2 and 24 hours were also performed for alloy 718 to establish the solvus-approach curve required for precipitation simulations. These treatments were done using 718 in two starting conditions, STOA material and as-received
(AR) material which had been given the same overaging treatment as the STOA samples. The overaged condition was chosen for two purposes: (i) to provide $\gamma^{\prime \prime}$ and $\gamma^{\prime}$ precipitates of a size that could be readily imaged via high resolution scanning electron microscopy and (ii) to assure that equilibrium (or near equilibrium) $\gamma^{\prime \prime} / \gamma^{\prime}$ volume fractions had been achieved after relatively-short times because only phase dissolution was involved during soaking at temperatures above those used for the initial overaging treatment. To verify that the heat treatment times were indeed conservative, simulations of phase dissolution were performed. ${ }^{[51]}$

The initial microstructures and those developed during the various Gleeble ${ }^{\circledR}$ and furnace heat treatments 
(for alloy 718 samples) were determined via scanning electron microscopy (SEM) following standard metallographic preparation, i.e., sectioning, grinding with $\mathrm{SiC}$ papers down to 800 grit, rough polishing with diamond, and final polishing with colloidal silica. The grain structures (and coarse precipitate dispersions) were documented using backscattered-electron (BSE) imaging in a Sirion or Quanta SEM (both manufactured by FEI, Hillsboro, OR). Each microscope was outfitted with a BSE detector manufactured by Deben UK Ltd. (London, UK); the accelerating voltage was $20 \mathrm{kV}$, working distance was $10 \mathrm{~mm}$, and the aperture size was $30 \mu \mathrm{m}$.

The very fine $\gamma^{\prime \prime}$ and $\gamma^{\prime}$ precipitates in alloy 718 samples were characterized after etching by swabbing with a solution of 33 pct. nitric acid, 33 pct. glacial acetic acid, 33 pct. deionized water, and 1 pct. hydrofluoric acid. Secondary-electron (SE) images of the etched samples were then obtained at magnifications between 100 and $300 \mathrm{kX}$ in a Zeiss Gemini SEM using an accelerating voltage of $0.5 \mathrm{kV}$, working distance between 3 and $4 \mathrm{~mm}$, and aperture size of $20 \mu \mathrm{m}$. Following imaging, point counting was applied to at least two micrographs for each condition in order to determine the volume fraction of precipitate. Coupled with measurements of the number of precipitates per unit area, the average circle-equivalent diameter was established.

\section{Modeling Procedures}

The kinetics of precipitation under constant coolingor heating-rate conditions were simulated using a fast-acting spreadsheet approach developed and applied previously to various PM superalloys and alloy 718. ${ }^{[16,29,38]}$ In brief, homogeneous nucleation, diffusional growth, and coarsening of precipitates were treated using classical expressions that were discretized and evaluated per a method originally developed by Kampmann and Wagner. ${ }^{[52]}$ This method comprises steps of nucleation and growth that are used to populate a series of bins, each with a given size of precipitate. Concurrent coarsening of the particles within each bin is also implicitly incorporated by including a Gibbs-Thomson correction for the matrix concentration at the matrix-precipitate interface. Key material inputs consist of the pertinent phase equilibria (equilibrium volume fraction as a function of temperature), phase compositions, bulk free energy of transformation, volumetric elastic strain energy and precipitate "shape factor" (for $\gamma^{\prime \prime}$ in alloy 718 which exhibits a high misfit with the $\gamma$ matrix and is oblate in shape), matrix-precipitate interface energy, and effective diffusivity for the rate-controlling solute (including suitable adjustments for the "off-diagonal" influence of other solutes). Techniques to determine the material coefficients and specific values for IN-100, LSHR, and 718 are given in References 29, 38 and 53.

Because of its importance with regard to the interpretation of $\mathrm{DSC} /$ specific heat measurements in particular, two complimentary techniques (described in detail and applied to various superalloys in Reference 53) were used in the present work to quantify the enthalpy $\Delta H^{*}$ (in $\mathrm{J}$ per gram or $\mathrm{J}$ per mol of precipitate) associated with the precipitation (or dissolution) reaction. In brief, the first method, pertaining specifically to a superalloy that has been solution treated in the single-phase $\gamma$ field, enables the determination of an average enthalpy. It consists of two steps. First, the area (heat generated in $\mathbf{J} /$ g) between an experimental specific-heat-vs-temperature ( $c$ vs $T)$ curve and a hypothetical baseline $\left(c_{b} v s T\right)$ which would represent behavior in the absence of precipitation (or dissolution) is measured. Second, the volume fraction of precipitate formed over the temperature interval for which the thermal energy was determined is estimated (by direct measurement or modeling). Knowledge of the solvus temperature $T_{\mathrm{s}}$ (and the fact that the bulk free energy of transformation $\Delta G^{*}$ vanishes here) enables the determination of the entropy of transformation, i.e., $\Delta S^{*}=\Delta H^{*} / T_{\mathrm{s}}$, and thus a simple expression for $\Delta G^{*}$ :

$$
\Delta G^{*}=\Delta H^{*}-T \Delta S^{*}=\Delta H^{*}\left(1-\left(T / T_{\mathrm{s}}\right)\right)
$$

The second approach for estimating $\Delta G^{*}$ (and hence $\left.\Delta H^{*}\right)$ consisted of the application of the more general Gibbs equation from solution thermodynamics. For a superalloy in which the $\gamma^{\prime}$ (or $\gamma^{\prime \prime}$ ) precipitate is lean in the rate-limiting solute controlling nucleation, this relation is as follows ${ }^{[53]}$.

$$
\Delta G^{*}\left(\gamma \rightarrow \gamma^{\prime}\right)=-\frac{\left.\left(C_{\gamma}-C_{\gamma^{\prime}}\right) \mathrm{RT} \ln \left[1-C_{\gamma}\right) /\left(1-C_{\mathrm{M}}\right)\right]}{C_{\gamma}\left[1+\partial \ln v / \partial \ln C_{\gamma}\right]}
$$

In Eq. [2], $C_{\gamma}$ and $C_{\gamma^{\prime}}$ denote the equilibrium concentrations of the rate-limiting solute in the $\gamma$ matrix and $\gamma^{\prime}$ precipitate, respectively, $\mathrm{C}_{\mathrm{M}}$ is the instantaneous composition of the $\gamma$ matrix, and $R$ is the gas constant. The bracketed term in the denominator is the thermodynamic factor (TF), sometimes referred to as the non-ideality factor, in which $\mathrm{v}$ is the activity coefficient for the rate-limiting solute in the $\gamma$ matrix. For an ideal solution, TF is identically equal to unity. The values of $\mathrm{TF}$ for the program alloys were obtained from previous calculations $^{[53]}$ and were supplemented by selected additional CALPHAD calculations. For $\gamma^{\prime \prime}$ precipitation, an expression identical to Eq. [2] applies with $C_{\gamma^{\prime}}$ replaced by $C_{\gamma^{\prime \prime}}$.

\section{RESULTS}

The principal results from this research consisted of measurements of the specific heat as a function of temperature for the PM alloys (IN-100 and LSHR) and the wrought alloy 718 , microstructure observations from Gleeble ${ }^{\circledR}$ heat treatments for alloy 718 , and microstructures in 718 samples given various furnace heat treatments to establish its solvus-approach curve(s). 


\section{A. Specific Heat of IN-100 and LSHR}

The broad temperature dependence of the specific heat (c) was similar for IN-100 and LSHR (Figure 3), as well as prior measurements for Mar-M200, Mar-M247, and Rene $80 .{ }^{[54]}$ For both sets of the present data, $c$ increased at a relatively-low rate at temperatures $T$ below $\sim 1000 \mathrm{~K}$, and then at a rate which increased with temperature. This trend was due to the evolution of the precipitate volume fraction at $1000 \mathrm{~K} \leq T \leq T_{\gamma^{\prime}}$. To emphasize and quantify such behavior, therefore, a hypothetical baseline joining the low-temperature and supersolvus measurements has been drawn in Figures 3(a) and (b). The baseline approximated the variation of $c$ with temperature in the absence of precipitate dissolution (during heating to the solvus) or formation (during cooling from the solvus). For pre-aged material, precipitates dissolve (endothermically) during heating, resulting in additional power required to maintain the prescribed rate, and thus values of $c$ that are greater than that indicated by the baseline. By contrast, precipitates are formed during cooling from above $T_{\gamma^{\prime}}$ as a result of a lowering of Gibbs free energy (and thus a corresponding exothermic reaction), leading to a reduction of required power input but under decreasing temperature conditions. This situation also gives rise to positive increments in $c$ relative to the hypothetical baseline.

For the most part, the $c$ vs $T$ results for each PM alloy (Figure 3) showed similar behavior during heating and cooling, thus indicating that the rate of precipitate dissolution during heating was comparable to the rate of formation during cooling from above $T_{\gamma^{\prime}}$. As will be discussed in Section IV, this similarity was indicative of conditions which deviated relatively little from the expected phase fractions corresponding to equilibrium for the heating/cooling rates used in the present experiments. For this reason, differences between the measured values of $c$ and the baseline thus provided an approximate measure of the solvus-approach curve; i.e., the variation of $\gamma^{\prime}$ fraction as a function of temperature.
The only noticeable differences between heating and cooling results were noted at $T \sim 1100 \mathrm{~K}$ to $1250 \mathrm{~K}$ for LSHR and near $T_{\gamma^{\prime}}$ for both alloys. The deviation at $1100 \mathrm{~K}$ to $1250 \mathrm{~K}$ for LSHR likely resulted from the dissolution of the measurable volume fraction of tertiary $\gamma^{\prime}$ precipitates that had been developed during the 8 hour aging treatment at $1089 \mathrm{~K}$ prior to DSC (Figure 1(b)). This tendency was avoided for IN-100 because its starting condition was developed solely by supersolvus solution treatment and air cooling without a final age, thus resulting in a small fraction of (low-temperature) tertiary $\gamma^{\prime}$ (Figure 1(a)).

The difference in $c$ vs $T$ trends near $T_{\gamma^{\prime}}$ for both alloys can be readily explained by two factors: (i) the need to exceed the equilibrium solvus to complete precipitate dissolution during heating at a finite rate and (ii) the requirement of some degree of undercooling below the equilibrium solvus to develop sufficient supersaturation for the nucleation of $\gamma^{\prime}$. As will be discussed in Section IV, the measured degree of undercooling provided a useful metric to assess the accuracy of DSC in quantifying on-cooling precipitation kinetics.

\section{B. Specific Heat of 718}

Compared to the PM superalloys, $c$ vs $T$ results for alloy 718 showed a number of different behaviors which highlighted the usefulness of DSC as a tool to probe precipitation (and dissolution) behavior of complex multi-phase alloys.

As expected, the on-heating behavior of 718 was dependent on starting condition. For a heating rate of 5 $\mathrm{K} / \mathrm{min}$, for example, the $c$ vs $T$ trends for each of the three starting conditions (ST, STA, and STOA) were similar at temperatures of $\sim 775 \mathrm{~K}$ and below (Figure 4(a)). These observations suggested that the specific heat in the absence of phase transformation for a microstructure of 100 pct. $\gamma$ (ST) was similar to that for microstructures consisting of $\gamma, \gamma^{\prime \prime}$, and $\gamma^{\prime}$ (STA, STOA).

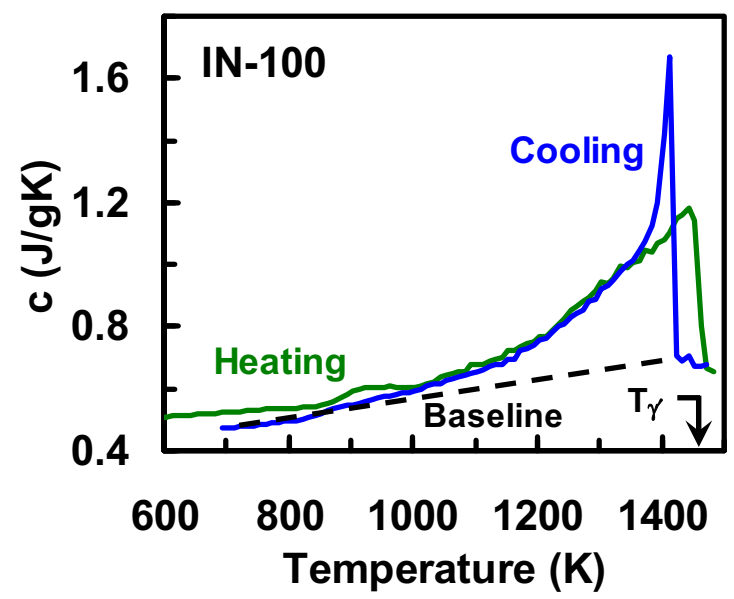

(a)

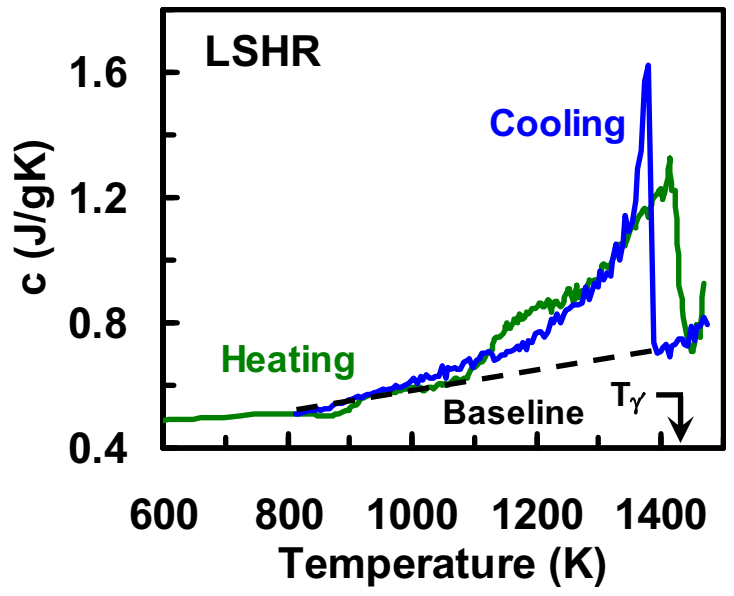

(b)

Fig. 3- Specific-heat data for conditions comprising heating or cooling for the PM alloys (a) IN-100 and (b) LSHR. 


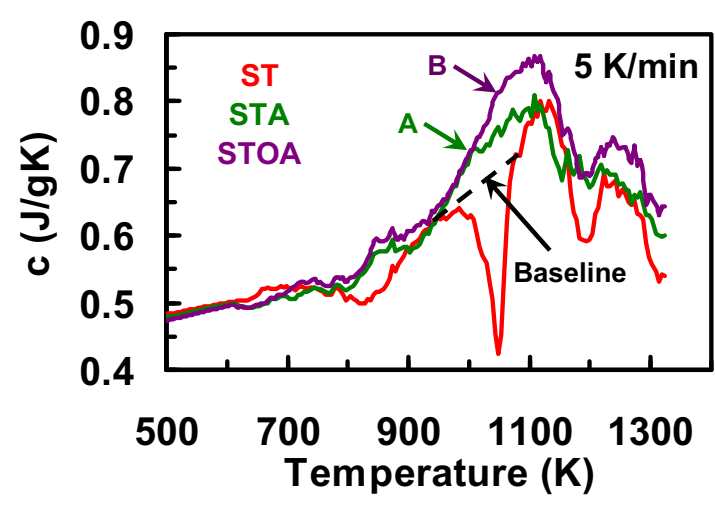

(a)

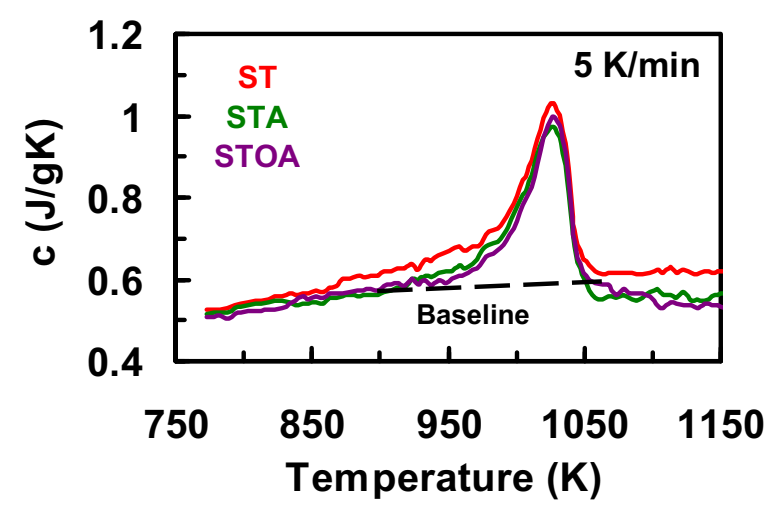

(b)

Fig. 4 -Specific-heat data for alloy 718 with various initial microstructures (ST, STA, STOA) measured under $(a)$ on-heating or (b) on-cooling conditions at a constant rate of $5 \mathrm{~K} / \mathrm{min}$.

In contrast to the low-temperature observations, a number of differences were found for the three microstructural conditions at $T \geq 775 \mathrm{~K}$ (Figure 4(a)). For instance, the ST sample revealed two exothermic valleys at temperatures between $775 \mathrm{~K}$ and $\sim 1080 \mathrm{~K}$. (When precipitate formation/exothermic reaction occurs during heating, less power is required compared to the standard sample, and a trough is produced in the $c$ vs $T$ curve.) As will be discussed in Section IV, the first of these features was related to the precipitation of $\gamma^{\prime}$ and the second to a predominance of $\gamma^{\prime \prime}$ precipitation over $\gamma^{\prime}$ dissolution. A "baseline" for the lower temperature trough was formed naturally by the corresponding overlying curves for STA/STOA samples. An approximate baseline for the $\gamma^{\prime \prime}$ trough between $\sim 950 \mathrm{~K}$ and $1080 \mathrm{~K}$ was established at the lower end by the intersection of the curves for all three conditions and at the upper end by the inflection point in the ST curve. Modeling results in Section IV indicated that this point was very close to the temperature at which dissolution of $\gamma^{\prime \prime}$ began.

The on-heating $c$ vs $T$ results for the STA and STOA samples, by contrast, showed noticeable changes in slope at the points indicated by the letters A and B, respectively, in Figure 4(a). Preliminary calculations suggested that these features were due to the dissolution of $\gamma^{\prime}$ and $\gamma^{\prime \prime}$ in the pre-aged samples, with higher temperatures required to initiate the process for the coarser (STOA) starting microstructure. These behaviors and the complex microstructure evolution at $T \geq$ $1080 \mathrm{~K}$, at which the dissolution of $\gamma^{\prime}$ and $\gamma^{\prime \prime}$ is completed and $\delta$ is precipitated (or transformed from $\gamma^{\prime \prime}$ ) and then dissolved, are the subject of future research.

Not surprisingly, the $c$ vs $T$ behavior for cooling at 5 $\mathrm{K} / \mathrm{min}$ after solution treatment above the $\delta$ solvus $(\sim 1300 \mathrm{~K})$ was very similar for all three starting conditions (ST, STA, and STOA) (Figure 4(b)). Each of the samples showed an initial deviation from linearity at $\sim 1065 \mathrm{~K}$ and a peak at $1027 \mathrm{~K}$. At yet lower temperatures, the specific heat showed a continuous decrease. The baseline for these on-cooling results was not as obvious as it was for the PM superalloys, but an approximate estimate is shown in Figure 4(b).

The $c$ vs $T$ observations during heating or cooling at a higher rate $(10$ to $20 \mathrm{~K} / \mathrm{min})$ were similar to those observed for $5 \mathrm{~K} / \mathrm{min}$. In particular, during heating at 10 $\mathrm{K} / \mathrm{min}$, two exothermic troughs were noted for the ST sample, and the signature of the onset of dissolution of $\gamma^{\prime \prime}$ and $\gamma^{\prime}$ for the STA and STOA samples (at corresponding points A and B) could be discerned (Figure 5(a)). Similarly, each of the on-cooling $c$ vs $T$ plots (Figure 5(b)) exhibited a "spike", whose breadth increased with cooling rate and whose peak was located at a temperature that decreased with increasing cooling rate. These trends were likely associated with the occurrence of precipitation over a larger range of temperature and a decrease in the amount of precipitate with increasing cooling rate. These observations were similar to those of Niang et al. ${ }^{[19]}$ using DTA, and Agazhanov et al. ${ }^{[55]}$ who applied DSC to determine the specific-heat of 718 during cooling at $10 \mathrm{~K} / \mathrm{min}$ following supersolvus solution heat treatment (SSHT) (Figure 5(b)).

\section{Microstructure Observations from Gleeble ${ }^{\circledR}$ Heat Treatments}

Samples of 718 subjected to direct-resistance heat treatment in a Gleeble ${ }^{\circledR}$ (plus water quenching) provided insight into the microstructures developed during intermediate stages in the DSC experiments and thus yielded quantitative information needed for the comparison of specific-heat data and mean-field precipitation-modeling predictions discussed below (Section IV). First, SE and BSE images for an ST sample heated to $1073 \mathrm{~K}$ at $5 \mathrm{~K} / \mathrm{min}$ (Figures 6(a) and (b), respectively) showed a number of precipitates which were likely $\gamma^{\prime \prime}$ (and perhaps some $\gamma^{\prime}$ ), as well as an absence of needle-like $\delta$ precipitates. The area fraction of the $\gamma^{\prime \prime} / \gamma^{\prime}$ precipitates was 0.072 , and their average CED was 6.5 nm. A second ST sample heated at $5 \mathrm{~K} / \mathrm{min}$ and water quenched at $1173 \mathrm{~K}$ revealed an absence of all precipitates, thus suggesting the complete dissolution 


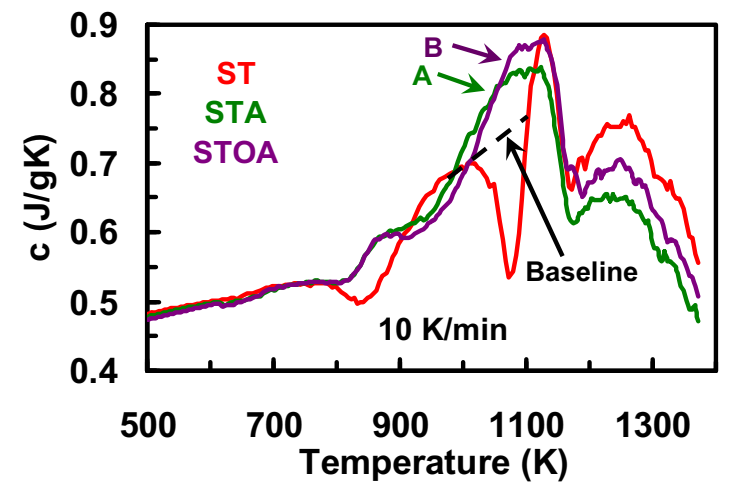

(a)

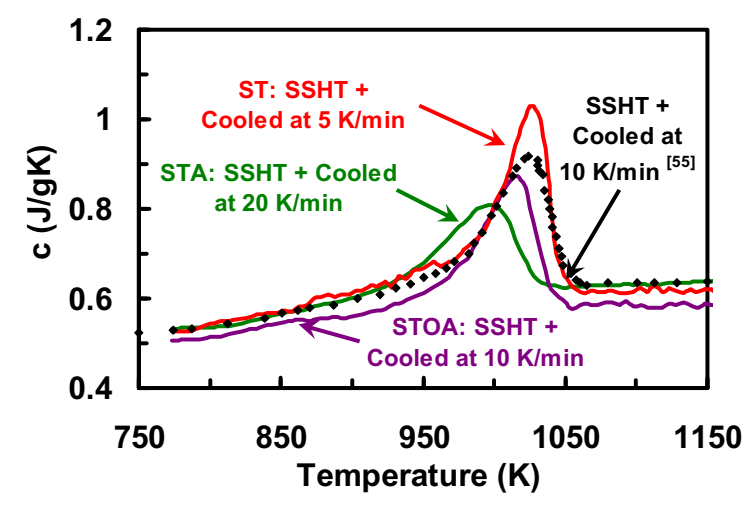

(b)

Fig. 5- Specific-heat data for alloy 718 with various initial microstructures (ST, STA, STOA) measured under $(a)$ on-heating conditions at a constant rate of $10 \mathrm{~K} / \mathrm{min}$ or $(b)$ on-cooling conditions at a constant rate of 5,10 , or $20 \mathrm{~K} / \mathrm{min}$ following super- $\delta$-solvus solution treatment (SSHT). The results in $(b)$ are compared to prior on-cooling measurements of Agazhanov et al. ${ }^{[55]}$ at a rate of $10 \mathrm{~K} / \mathrm{min}$.
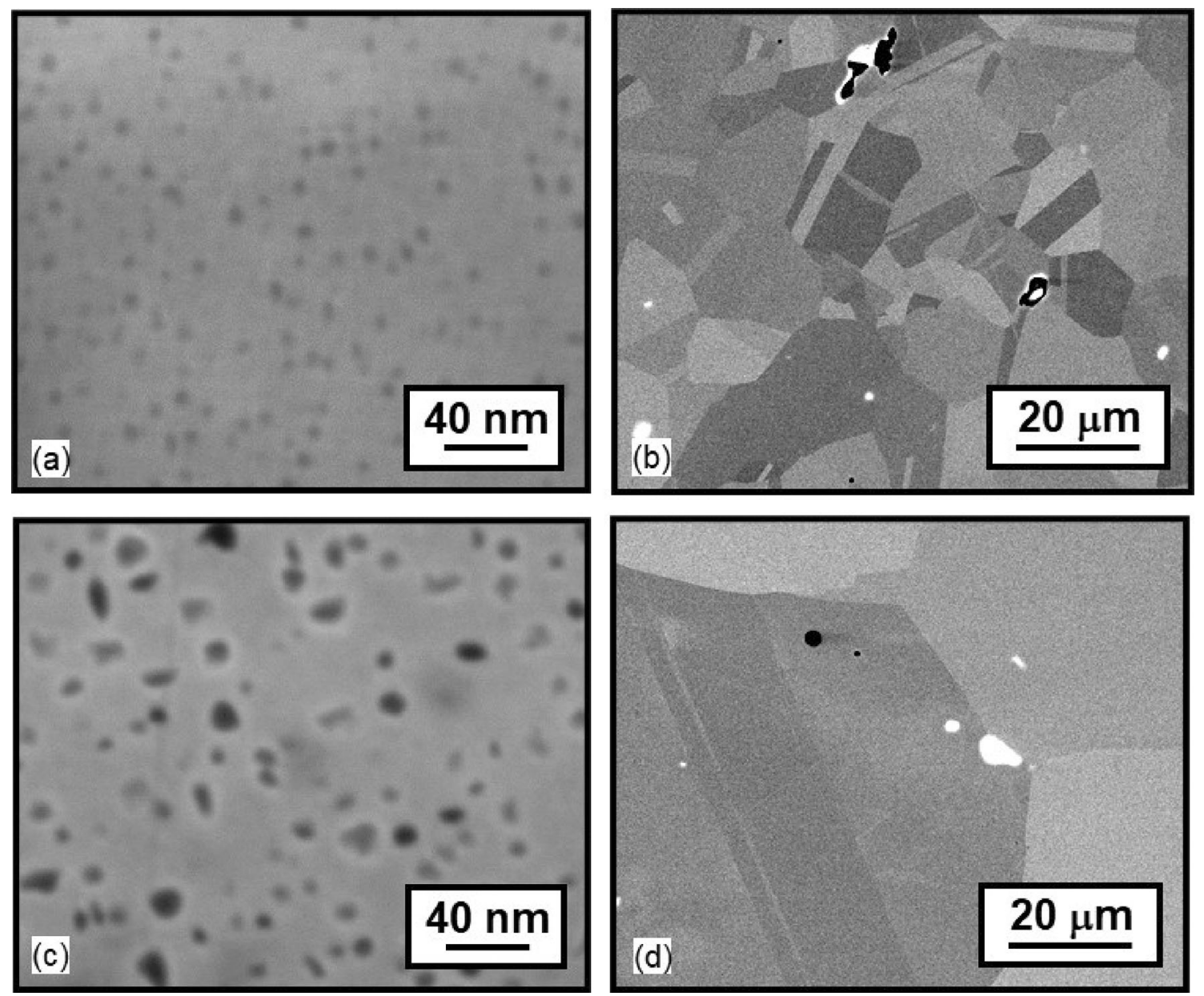

Fig. 6-Microstructure observations for direct-resistance heat treated 718 samples: (a) ST sample heated at $5 \mathrm{~K} / \mathrm{min}$ to $1073 \mathrm{~K}$ and water quenched or $(b)$ super- $\delta$-solvus solution-treated sample which was cooled at $5 \mathrm{~K} / \mathrm{min}$ to $993 \mathrm{~K}$ and then water quenched. The microstructures were revealed by $(\mathrm{a}, c) \mathrm{SE}$ or $(\mathrm{b}, d)$ BSE imaging.

of the $\gamma^{\prime \prime} / \gamma^{\prime}$ which had formed at lower temperatures, at least as indicated by the resolution capability of a Zeiss Gemini SEM.
SE and BSE micrographs for a super- $\delta$-solvus solution-treated sample which was cooled at $5 \mathrm{~K} / \mathrm{min}$ and water quenched upon reaching $993 \mathrm{~K}$ showed a 
distribution of $\gamma^{\prime \prime}$ (and possibly some $\gamma^{\prime}$ ) precipitates (Figure 6(c)). The volume fraction was 0.094 , and the average CED was $10.7 \mathrm{~nm}$ (Figure 6(c)). No $\delta$ needles were observed, however (Figure 6(d)).

\section{Solvus Approach Curve for 718}

Although the $\gamma^{\prime \prime}$ and $\gamma^{\prime}$ phases could not be differentiated due to their fine size (and perhaps stereological effects for the oblate $\gamma^{\prime \prime}$ ), high-resolution SEM images did provide good estimates of the temperature dependence of the overall volume fraction of $\gamma^{\prime \prime}+\gamma^{\prime}$. Typical SE images for samples that had been first supersolvus solution treated, water quenched, and then aged 24 hours at both $993 \mathrm{~K}$ and the $893 \mathrm{~K}$ prior to further isothermal exposure at various temperatures are shown in Figure 7. Here, a decrease in total $\gamma^{\prime \prime}+\gamma^{\prime}$ with increasing temperature was apparent. In addition, coarsening of what is likely $\gamma^{\prime \prime}$ (based on its noticeable shape anisotropy) was evident at temperatures of 1089 $\mathrm{K}$ and higher. Lower-magnification images (Figure 8) also indicated that $\delta$-phase formation did not occur until $T \geq 1144 \mathrm{~K}$ and demonstrated the effectiveness of
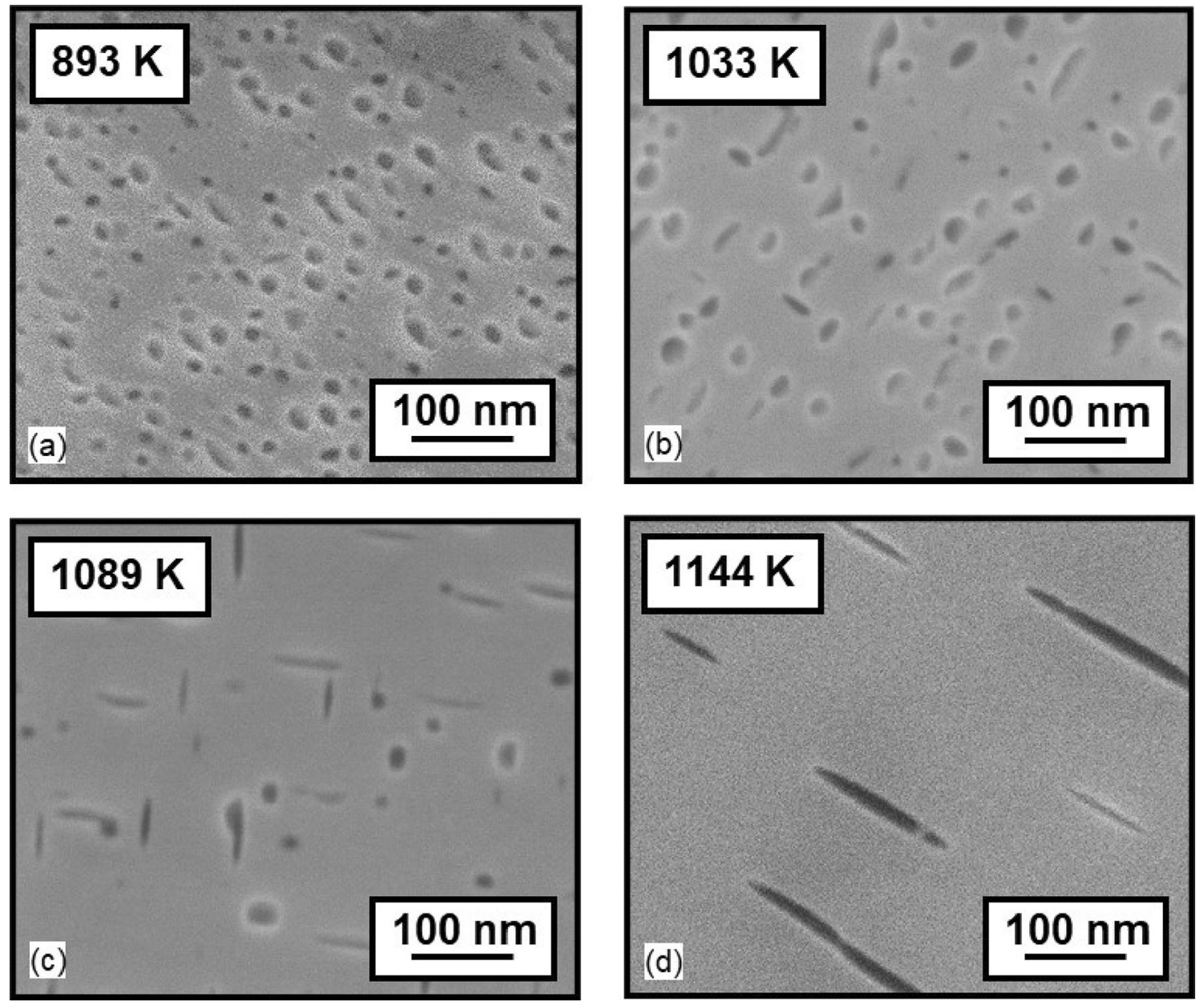

Fig. 7-High-magnification SE images of alloy 718 samples with $(a)$ an initial STOA microstructure $(1339 \mathrm{~K} / 1 \mathrm{~h}+\mathrm{WQ}+993 \mathrm{~K} / 24 \mathrm{~h}+893$ $\mathrm{K} / 24 \mathrm{~h}$ ) which were subsequently furnace heat treated at (b) $1033 \mathrm{~K} / 4 \mathrm{~h},(c) 1089 \mathrm{~K} / 2 \mathrm{~h}$, or $($ d $) 1144 \mathrm{~K} / 2 \mathrm{~h}$. 

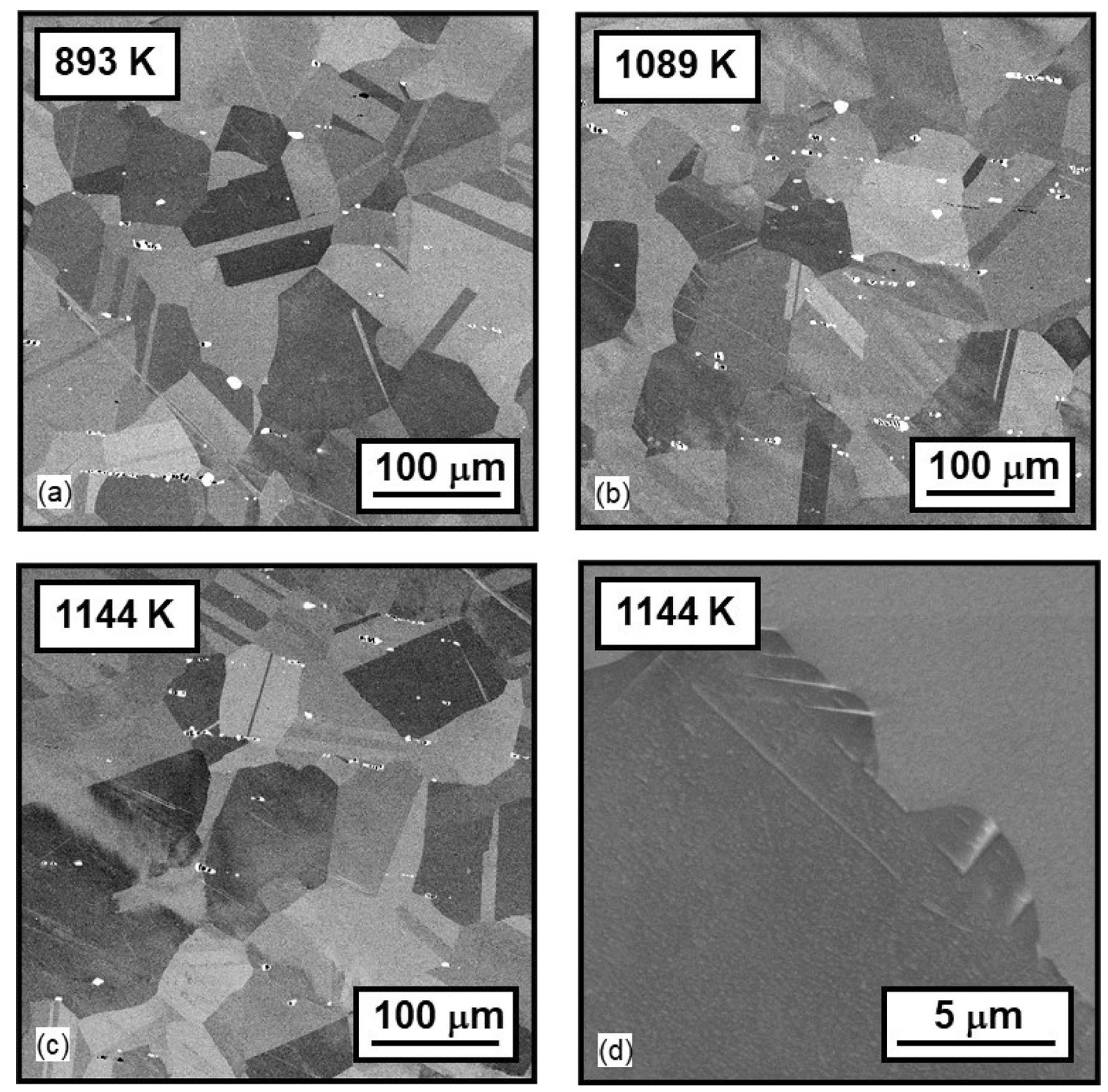

Fig. 8-BSE images of alloy 718 samples with (a) an initial STOA microstructure (1339 K/1 h + WQ + $993 \mathrm{~K} / 24 \mathrm{~h}+893 \mathrm{~K} / 24 \mathrm{~h})$ which were subsequently furnace heat treated at $(b) 1089 \mathrm{~K} / 2 \mathrm{~h}$, or $(c, d) 1144 \mathrm{~K} / 2 \mathrm{~h}$.

points versus red data points in Figure 11. The source of this difference may lay in the smaller sizes of the precipitates that were developed and thus difficulty in the imaging all of the particles via high-resolution SEM. The effect of the uncertainty in the precise solvus-approach curve on predictions from precipitation simulations is thus treated in Section IV.

\section{DISCUSSION}

The utility of specific-heat measurements for the interpretation of precipitation kinetics requires two principal factors: (i) a relationship between the heat that is generated or absorbed during DSC and the volume fraction of precipitate and (ii) the determination of the portion of the total heat generated which is actually associated with phase transformation per se. The method by which this is accomplished and its application to IN-100, LSHR, and 718 are summarized in the following sections.

\section{A. Relation Between Heat of Transformation and Precipitation}

For PM superalloys such as IN-100 and LSHR, for which a single precipitate phase $\left(\gamma^{\prime}\right)$ is formed, the relationship between the heat generated due to precipitation and the fraction of precipitate is readily derived from a simple heat balance, i.e.,

$$
\mathrm{H}_{\gamma^{\prime}}^{*} \mathrm{dm}_{\gamma^{\prime}}=m_{\mathrm{s}}\left(c-c_{\mathrm{b}}\right) \mathrm{d} T
$$



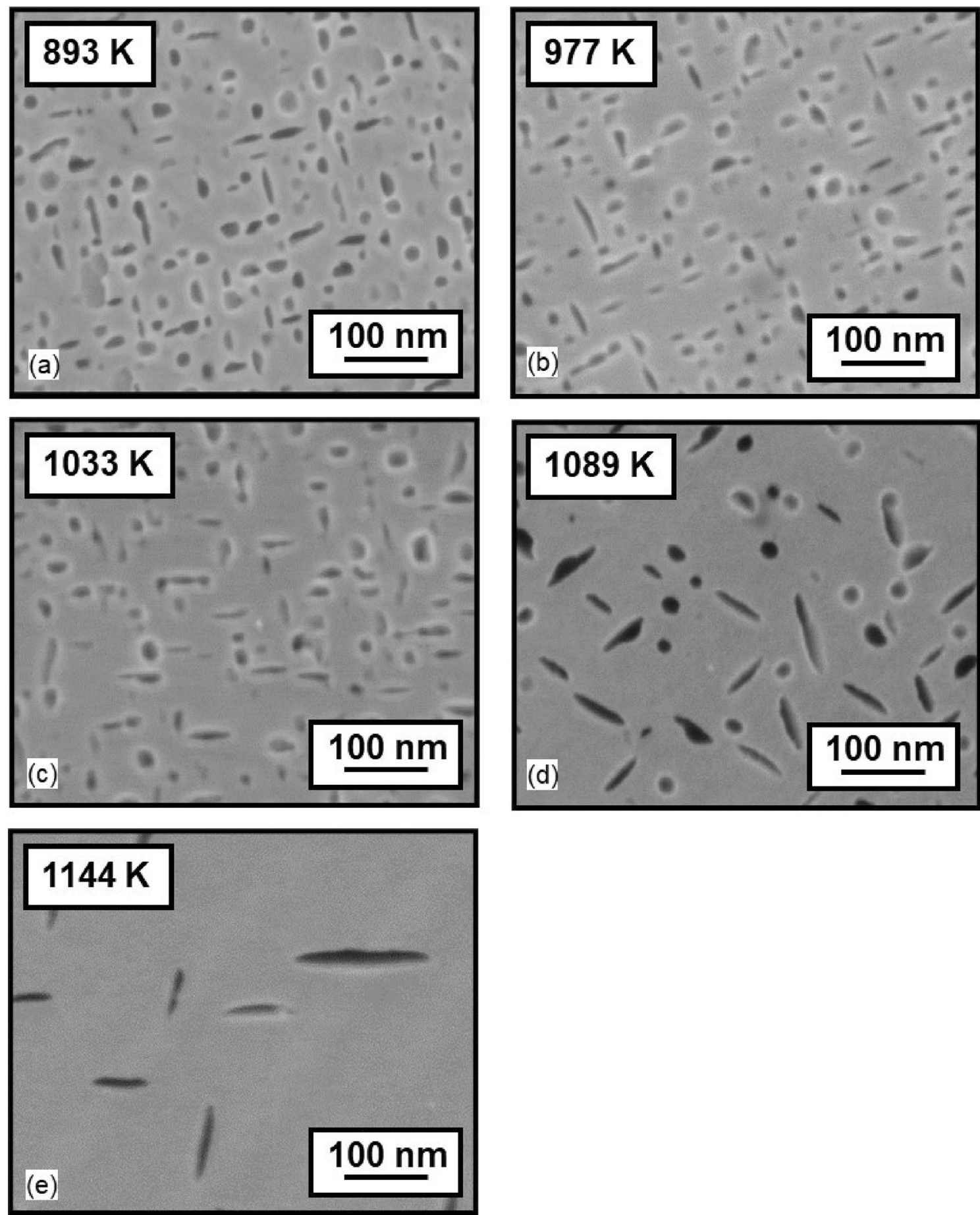

Fig. 9-High-magnification SE images of as-received 718 samples which were $(a)$ initially overaged $(993 \mathrm{~K} / 24 \mathrm{~h}+893 \mathrm{~K} / 24 \mathrm{~h})$ and then furnace heat treated at $(b) 977 \mathrm{~K} / 4 \mathrm{~h},(c) 1033 \mathrm{~K} / 4 \mathrm{~h},(d) 1089 \mathrm{~K} / 2 \mathrm{~h}$, or $(e) 1144 \mathrm{~K} / 2 \mathrm{~h}$.

Here, $H_{\gamma^{\prime}}^{*}$ denotes the enthalpy of formation of the $\gamma^{\prime}$ precipitate (in $\mathrm{J} / \mathrm{g}$ ), which is assumed to be a constant, $\mathrm{dm}_{\gamma^{\prime}}$ is the increment in mass of the precipitate, $\mathrm{m}_{\mathrm{s}}$ is the mass of the DSC sample (assumed to be constant), $c-c_{b}$ is the overall specific heat $(c)$ less that of the baseline $\left(c_{b}^{\prime}\right.$ i.e., the specific heat in the absence of precipitation). Integrating and rearranging Eq. [3a] results in an expression for the mass fraction of $\gamma^{\prime}, f_{m \gamma \gamma}$ :

$$
\int_{T_{n}}^{T}\left(\mathrm{dm}_{\gamma^{\prime}} / m_{\mathrm{s}}\right)=f_{m \gamma^{\prime}}(T)=\left[\int_{T_{n}}^{T}\left(c-c_{b}\right) \mathrm{d} T\right] / H_{\gamma^{\prime}}^{*}
$$

Equation [3b] reveals that $f_{\mathrm{m} \gamma^{\prime}}$ as a function of temperature $T$ is equal to the integrated area between the $c(T)$ curve and the baseline $c_{b}(T)$ over the limits $T_{\mathrm{n}}$ 

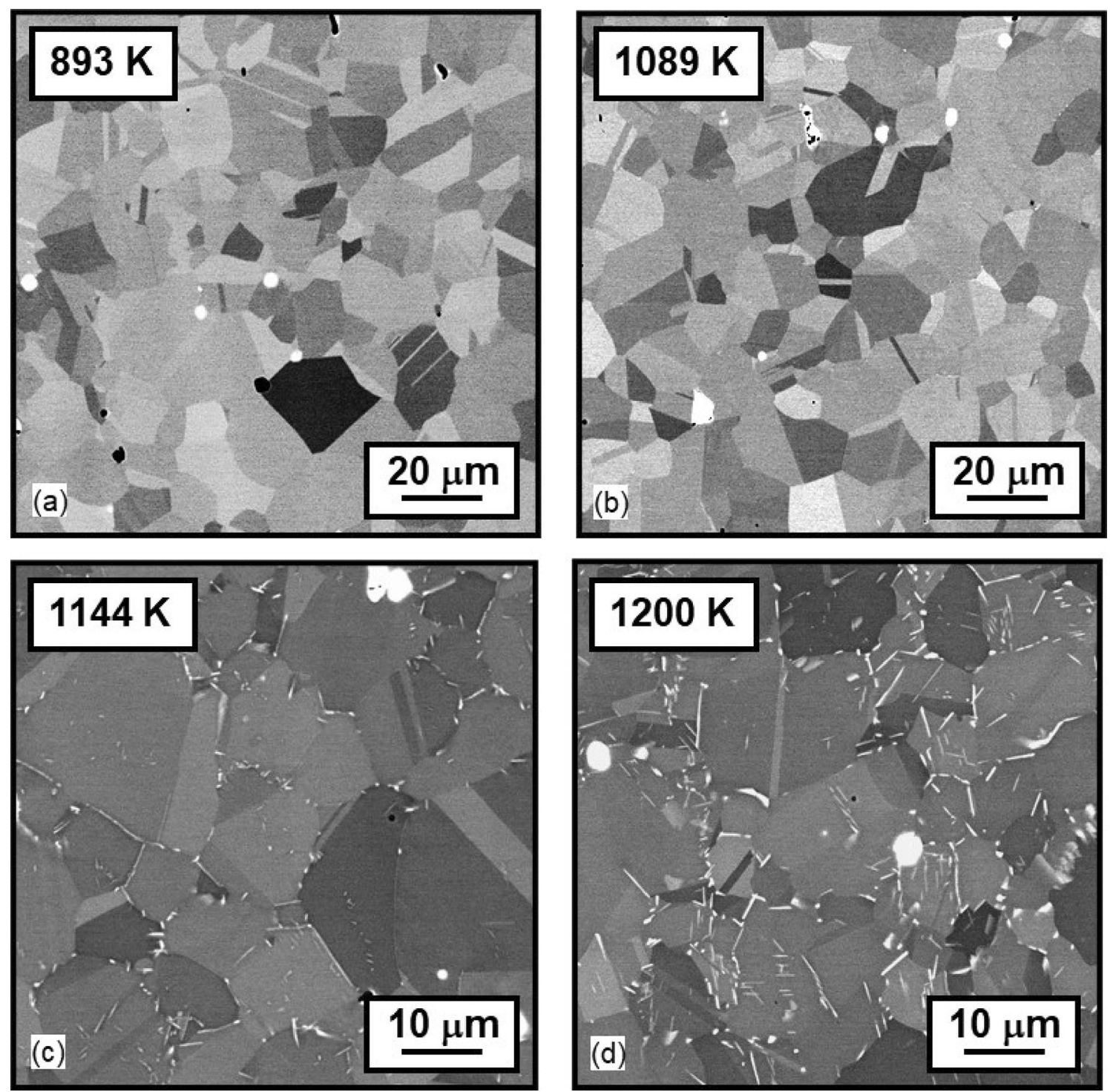

Fig. 10-BSE images of as-received 718 samples which were $(a)$ initially overaged $(993 \mathrm{~K} / 24 \mathrm{~h}+893 \mathrm{~K} / 24 \mathrm{~h})$ and then furnace heat treated at (b) $1089 \mathrm{~K} / 2 \mathrm{~h},($ c) $1144 \mathrm{~K} / 2 \mathrm{~h}$, or (d) $1200 \mathrm{~K} / 2 \mathrm{~h}$.

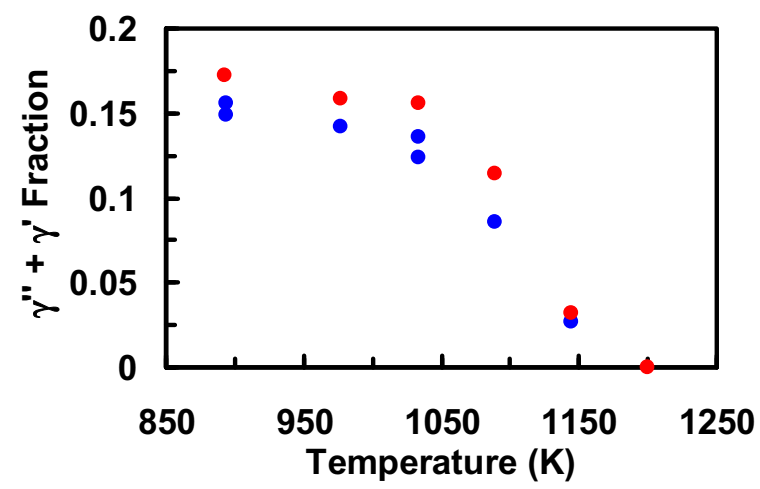

Fig. 11-Total volume fraction of $\gamma^{\prime \prime}+\gamma^{\prime}$ precipitates as a function of temperature. The red and blue data points correspond respectively to measurements for samples that were not or were given a super- $\delta$-solvus solution treatment prior to overaging (at $973 \mathrm{~K}$ and $873 \mathrm{~K}$ ) and final heat treatment at the temperatures indicated (Color figure online). (at which nucleation is observed to initiate) to $T$, divided by the enthalpy of formation.

To convert the mass fraction $f_{\mathrm{m} \gamma^{\prime}}$ to the volume fraction $f_{\gamma^{\prime}}$, the molar mass (gram molecular weight) and density of each phase are required. For IN-100, the molar masses of $\gamma$ and $\gamma^{\prime}$, based on the compositions in Reference 53, are 54.6 and $53.5 \mathrm{~g} / \mathrm{mol}$, respectively. Taking the density of the two phases to be equal, the molar volumes are approximately equal, and thus the volume fraction of $\gamma^{\prime}$ may be taken to be equal to the mass fraction of $\gamma^{\prime}$. For LSHR, the corresponding molar masses are $\sim 58.0$ and $57.7 \mathrm{~g} / \mathrm{mol}$. Assuming comparable density again, an equivalence between mass fraction of precipitate and volume fraction was taken to be a reasonable assumption as well.

For the case of 718 with both $\gamma^{\prime \prime}$ and $\gamma^{\prime}$ precipitates, a relation similar to Eq. [3a] is readily derived, i.e., 


$$
\begin{aligned}
& H_{\gamma^{\prime \prime}}^{*} \mathrm{~d} m_{\gamma^{\prime \prime}}+H_{\gamma^{\prime}}^{*} \mathrm{~d} m_{\gamma^{\prime}}=m_{\mathrm{s}}\left(c-c_{\mathrm{b}}\right) \mathrm{d} T, \\
& \text { or } H_{\gamma^{\prime \prime}}^{*} \mathrm{df}_{\mathrm{m} \gamma^{\prime \prime}}+H_{\gamma^{\prime}}^{*} \mathrm{df}_{\mathrm{m} \gamma^{\prime}}=\left(c-c_{\mathrm{b}}\right) \mathrm{d} T,
\end{aligned}
$$

in which $m_{\gamma^{\prime \prime}}, \mathrm{d}_{\mathrm{m} \gamma^{\prime \prime}} / \mathrm{m}_{\mathrm{s}}=\mathrm{d} f_{\mathrm{m} \gamma^{\prime \prime}}$, and $H_{\gamma^{\prime \prime}}^{*}$ represent the mass, mass fraction increment, and enthalpy of formation of $\gamma^{\prime \prime}$. Because there are two unknown mass fractions $\left(f_{\mathrm{m} \gamma^{\prime \prime}}\right.$ and $\left.f_{\mathrm{m} \gamma^{\prime}}\right)$, Eq. [4b] cannot be inverted as was done for the case of the PM alloys. Rather, the differential form of this relation was applied to determine if precipitation-simulation predictions of the fractions of $\gamma^{\prime \prime}$ and $\gamma^{\prime}$ as a function of temperature were consistent with specific-heat measurements, i.e.,

$$
c-c_{\mathrm{b}}=H_{\gamma^{\prime \prime}}^{*}\left(\mathrm{df}_{\mathrm{m} \gamma^{\prime \prime}} / \mathrm{d} T\right)+H_{\gamma^{\prime}}^{*}\left(\mathrm{df}_{\mathrm{m} \gamma^{\prime}} / \mathrm{d} T\right)
$$

For alloy 718, the molar masses of $\gamma, \gamma^{\prime}$, and $\gamma^{\prime \prime}$ are $58.0,57.7$, and $65.1 \mathrm{~g} / \mathrm{mol}$, respectively. ${ }^{[38]}$ Although the molar mass of $\gamma^{\prime \prime}$ is considerably greater than that of $\gamma$ and $\gamma^{\prime}$, it is likely it has a correspondingly-greater density due to its large niobium content. Thus, it was assumed that the volume fractions of each precipitate were equal to their mass fractions within engineering accuracy.

The applicability of the assumed baselines to estimate $c_{b}$ was confirmed by comparing the slopes estimated for several of the present datasets to those from specific-heat data for the moderately-enriched, nominally-single-phase nickel-base alloys $600(\mathrm{Ni}-15 \mathrm{Cr}-7 \mathrm{Fe}$, in wt pet.) and Hastelloy $\mathrm{X}$ (Ni-22Cr-18Fe-9Mo-1.5Co-0.5W, in wt. pct.). ${ }^{[57]}$ This comparison (Figure 12) showed reasonably-good agreement, thereby providing justification for the present construction.

\section{B. Interpretation of Results for IN-100 and LSHR}

The applicability of specific-heat measurements to determine the kinetics of precipitation during cooling from above the $\gamma^{\prime}$ solvus was confirmed for the two PM alloys, IN-100 and LSHR. For each $\gamma-\gamma^{\prime}$ superalloy, the

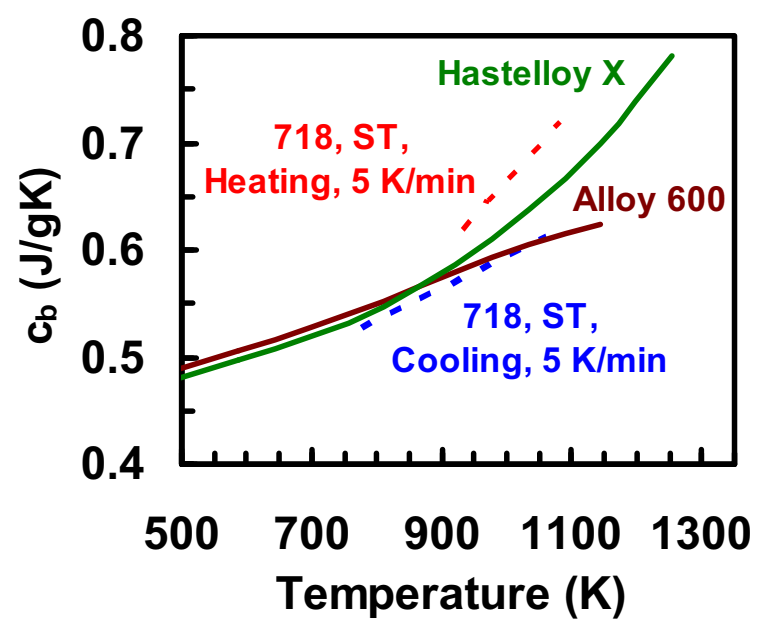

Fig. 12-Comparison of the baseline specific heat $\left(c_{b}\right)$ for 718 ST samples which were heated or cooled at $5 \mathrm{~K} / \mathrm{min}$ with the specific heat of nickel alloys 600 or Hastelloy X reported in the literature. ${ }^{[57]}$ volume fraction of $\gamma^{\prime}$ as a function of temperature was estimated from the measured on-cooling specific-heat data (Figure 3), the value of $H_{\gamma^{\prime}}^{*}$ (Table I) as determined by the methods summarized in Section II-C, and Eq. [3b]. In Figure 13, each of the DSC/specific-heat predictions (blue curves) are compared to the corresponding equilibrium $\gamma^{\prime}$ solvus-approach curve (SAC) (green) and predictions from nucleation-and-growth simulations (and accompanying input data) for secondary $\gamma^{\prime}$ (solid red curves) and tertiary $\gamma^{\prime}$ (broken red curve for LSHR). ${ }^{[18,29,53]}$ The shape of the SACs was based on a semi-empirical technique developed by Dyson ${ }^{[58]}$ and refined by Payton. ${ }^{[59]}$ It consists of fitting $f(T)$ measurements to the following analytical expression:

$$
f=-\frac{4 C_{\mathrm{o}}\left(1-\exp \left[\frac{Q_{\mathrm{S}}}{R}\left(\frac{T-T_{\gamma^{\prime}}}{T x T_{\gamma^{\prime}}}\right]\right)\right.}{1-4 C_{\mathrm{o}} \exp \left[\frac{Q_{\mathrm{s}}}{R}\left(\frac{T-T_{\gamma^{\prime}}}{T x T_{\gamma^{\prime}}}\right)\right]}
$$

Here, $4 \mathrm{C}_{\mathrm{o}}$ is the maximum volume fraction of $\gamma^{\prime}$ in the alloy (at $0 \mathrm{~K}$ ), and $Q_{\mathrm{s}}$ is a fitting parameter. The values of $4 \mathrm{C}_{\mathrm{o}}$ and $Q_{\mathrm{s}}$ for $\mathrm{IN}-100$ and LSHR are listed in Table I.

As expected from nucleation theory, the simulation predictions of $f_{\gamma^{\prime}}$ (red curves) and those derived from the DSC measurements (blue curves) both exhibited some degree of undercooling below $T_{\gamma^{\prime}}$ (point at which the green solvus-approach curve indicates $f_{\gamma^{\prime}}=0$ in Figure 13). The precise undercooling for nucleation of $\gamma^{\prime}$, as determined experimentally in synchrotron experiments, ${ }^{[29]}$ is also indicated for each material by the vertical arrow marked $T_{n}$. These arrows indicated that the simulations predicted the onset of nucleation within 1 or 2 kelvins, whereas the DSC results suggested that nucleation occurred at temperatures $\sim 20 \mathrm{~K}$ lower. This discrepancy in the DSC results may have arisen from difficulty in maintaining a constant cooling rate at high temperatures for those cases in which large levels of exothermic heating (associated with precipitation) occurred.

After nucleation, the simulation and DSC curves both indicated a moderate to high rate of increase in $f_{\gamma^{\prime}}$ to levels comparable or almost equivalent to that indicated by the SAC itself (Figure 13). Such rapid increases predicted in the simulations have also been experimentally corroborated in a quantitative fashion. ${ }^{[2]}$ As for the initial nucleation stage, however, the DSC curve lagged somewhat the simulated rise and subsequent drop

Table I. Equilibrium Solvus Approach Curve (SAC) Coefficients and Enthalpy Data for IN-100 and LSHR

\begin{tabular}{llc}
\hline Parameter & IN-100 & LSHR \\
\hline$T_{\gamma^{\prime}}(\mathrm{K})$ & 1458 & 1430 \\
$4 \mathrm{C}_{\mathrm{o}}$ & 0.602 & 0.535 \\
$Q_{\text {solv }}(\mathrm{kJ} / \mathrm{mol})$ & 75 & 60 \\
$H_{\gamma^{\prime}}^{*}\left(\mathrm{~J} / \mathrm{mol} \gamma^{\prime}\right)$ & 6907 & 7172 \\
$H_{\gamma^{\prime}}^{*}\left(\mathrm{~J} / \mathrm{g} \gamma^{\prime}\right)$ & 129.1 & 124.3 \\
\hline
\end{tabular}




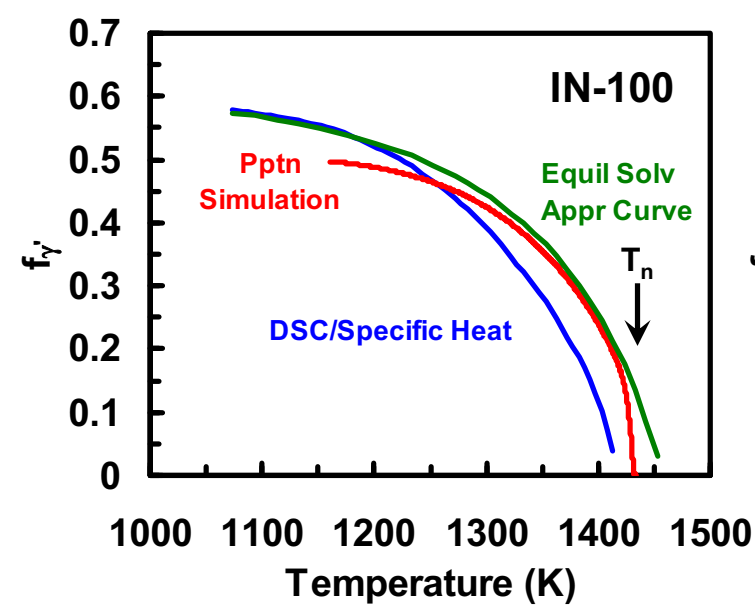

(a)

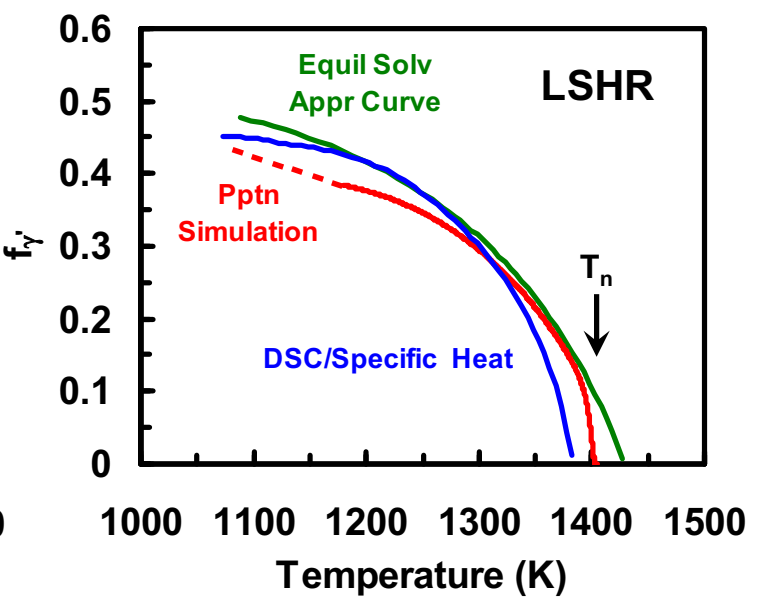

(b)

Fig. 13 - Comparison of the $\gamma^{\prime}$ volume fraction developed during cooling from above the solvus yemperature for $(a)$ IN-100 or $(b)$ LSHR. In each figure, the green curve corresponds to the equilibrium solvus approach curve, and the red and blue curves correspond respectively to simulation results for the precipitation of secondary $\gamma^{\prime}$ and experimental data derived from DSC/specific-heat measurements for a cooling rate of $15 \mathrm{~K} / \mathrm{min}$. In (b), the broken red line denotes the portion of the precipitation sequence for tertiary $\gamma^{\prime}$ (Color figure online).

relative to the SAC for both IN-100 and LSHR. This trend also suggested a degree of inertia in DSC even at temperatures $\sim 100$ to $250 \mathrm{~K}$ below $T_{\gamma^{\prime}}$. Nevertheless, at yet lower temperatures $\left(\sim 250 \mathrm{~K}\right.$ or greater below $\left.T_{\gamma^{\prime}}\right)$, at which the slow rate of tertiary $\gamma^{\prime}$ precipitation predominates, the DSC curve became similar to that from the simulation as indicated by the comparison for LSHR in Figure 13(b). Moreover, the difference in volume fraction between the simulation/DSC curves and the SAC curve for LSHR at $T=1083 \mathrm{~K}$ (i.e., $\sim 0.05$ ) was comparable to that mirrored by the heat absorbed during dissolution of "extra" tertiary $\gamma^{\prime}$ during reheating following an 8 hour aging treatment at this temperature; i.e., the "island" between the on-heating and on-cooling curves at $\sim 1175 \mathrm{~K}$ to $1225 \mathrm{~K}$ in Figure 3(b).

\section{Interpretation of Results for Alloy 718}

For alloy 718, the evolution of the volume fractions of $\gamma^{\prime \prime}$ and $\gamma^{\prime}$ for two cases was simulated and used to estimate the corresponding variation of $c-c_{b}$ with temperature per Eq. [4b]. These cases comprised the cooling of a sample following supersolvus solution treatment and the heating of an ST sample through the precipitation regime, both using a rate of $5 \mathrm{~K} / \mathrm{min}$.

\section{Input data for simulations}

A number of the key input parameters for the present cooling/heating simulations were identical to those used in previous analyses of precipitation under isothermal conditions (Table II). ${ }^{[23,38]}$ In this prior work, special attention was paid to the sensitivity of kinetic predictions to precipitate-matrix $\left(\gamma^{\prime \prime}-\gamma\right.$ and $\left.\gamma^{\prime}-\gamma\right)$ interface energies/elastic (misfit) strain energies, which play a key role in nucleation, and effective diffusivities, which control subsequent precipitate growth. In the present work, two key thermodynamic coefficients, which affect nucleation through their influence on the evolution of supersaturation and the bulk free energy of phase transformation during cooling or heating, were investigated. These consisted of the shape of the equilibrium SACs for $\gamma^{\prime \prime}$ and $\gamma^{\prime}$ and the magnitude of the thermodynamic factors (TF) for solutes in the $\gamma$ matrix.

The shapes of the SAC for the metastable $\gamma^{\prime \prime}$ phase and the stable $\gamma^{\prime}$ phase were both assumed to follow the analytical form given by Eq. [5]. The selection of the values of fitting coefficients $4 \mathrm{C}_{\mathrm{o}}$ and $Q_{\mathrm{s}}$ for each phase was guided by prior experimental measurements, ${ }^{[60,61]}$ CALPHAD calculations, ${ }^{[35,62]}$ and the present measurements for the $\gamma^{\prime \prime}+\gamma^{\prime}$ aggregate. For example, Figure 14(a) shows a comparison of prior measurements and possible analytical fits for $\gamma^{\prime \prime}$ and $\gamma^{\prime}$. The analytical fits using $4 \mathrm{C}_{\mathrm{o}}=0.13$ and $Q_{\mathrm{s}}=120 \mathrm{~kJ} / \mathrm{mol}$ for $\gamma^{\prime \prime}$ and $4 \mathrm{C}_{\mathrm{o}}=0.05$ and $Q_{\mathrm{s}}=75 \mathrm{~kJ} / \mathrm{mol}$ for $\gamma^{\prime}$ appeared to be reasonable. In addition, a comparison of the overall curve (obtained by adding the fit for each phase) with the present measurements of the total $\gamma^{\prime \prime}+\gamma^{\prime}$ fraction also showed good agreement (Figure 14(b)). Other, slightly-modified, versions of the fits (some of which are summarized in Table III and color coded in Figure 14(b)) provided reasonable alternatives as well, if not for the entire range of temperature then for a portion of it.

Values of the TFs for solutes which have been deduced to control nucleation of $\gamma^{\prime \prime}$ and $\gamma^{\prime}$ in 718, i.e., $\mathrm{Nb}$ and Ti, respectively, ${ }^{[38]}$ are summarized in Figure 15. These TFs were derived using CALPHAD calculations for $\mathrm{Nb}$ and $\mathrm{Ti}$ in solid solutions that pertain to PM $\gamma-\gamma^{\prime}$ superalloys $^{[53]}$ (round symbols) as well as alloy 718 (square symbols, present work). Although there was some scatter in the predictions, the trends for both $\mathrm{Nb}$ and Ti appeared similar for the two different classes of alloys.

Last, the consistency of the SACs and TFs was established by comparing predictions from Eqs. [1] and [2] for the dependence of $\Delta \mathrm{G}^{*}$ on temperature (and 
Table II. Key Input Parameters for 718 Simulations in Refs. ${ }^{[23]}$ and ${ }^{[38]}$

Value

$\gamma^{\prime \prime}$ Composition (At. pet)

$\gamma^{\prime}$ Composition (At. pct)

$\gamma^{\prime \prime}$ Solvus Temperature, $T_{\gamma^{\prime \prime}}(\mathrm{K})$

$\gamma^{\prime}$ Solvus Temperature, $T_{\gamma^{\prime}}(\mathrm{K})$

$\gamma^{\prime \prime}-\gamma$ Interface Energy $\left(\mathrm{mJ} / \mathrm{m}^{2}\right)$

$\gamma^{\prime}-\gamma$ Interface Energy $\left(\mathrm{mJ} / \mathrm{m}^{2}\right)$

$\gamma^{\prime \prime}$ Aspect Ratio (height:dia.)

$\gamma^{\prime \prime}$ Nucleation Factors, $\mathrm{K}_{\Delta \mathrm{G}^{*}}, \mathrm{~K}_{\beta^{*}}, \mathrm{~K}_{\mathrm{z}}$

$\mathrm{Nb} \mathrm{TF}$ for $\gamma^{\prime \prime}$ Nucleation (-)

Ti TF for $\gamma^{\prime}$ Nucleation (-)

$\Delta G_{\text {el }}$ for $\gamma^{\prime \prime}-\gamma$ Misfit $(\mathrm{MPa})$

Effective Diffusivity of $\mathrm{Cr}\left(\mathrm{m}^{2} / \mathrm{s}\right)$

Effective Diffusivity of $\mathrm{Al}\left(\mathrm{m}^{2} / \mathrm{s}\right)$

1.9Fe-2.18Cr-2.0Mo-18.5Nb-4.3Ti-1.2Al-bal. Ni
$2.3 \mathrm{Fe}-1.95 \mathrm{Cr}-1.1 \mathrm{Mo}-7.38 \mathrm{Nb}-7.86 \mathrm{Ti}-8.95 \mathrm{Al}-$ bal. Ni
1203
1123
62
40
0.5
$0.75,1,1.155$
1.1
1.3
70
$4.57 \times 10^{-5} \operatorname{Exp}(-34,280 / \mathrm{T})$
$3.94 \times 10^{-4} \operatorname{Exp}(-34,280 / \mathrm{T})$

$T$ denotes temperature in kelvins.

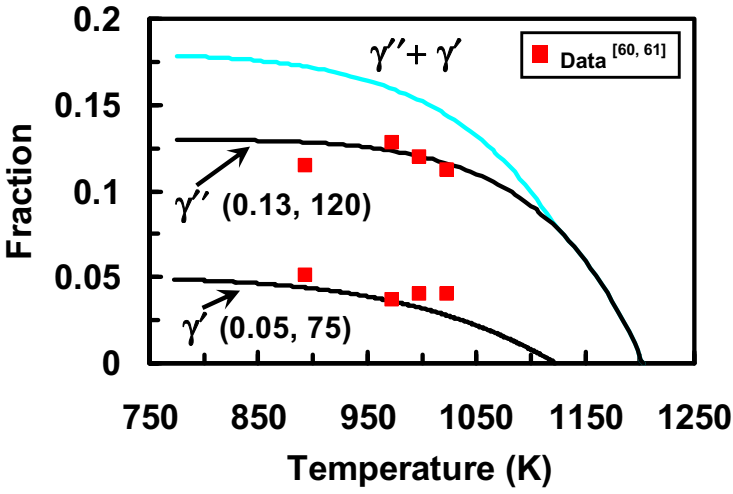

(a)

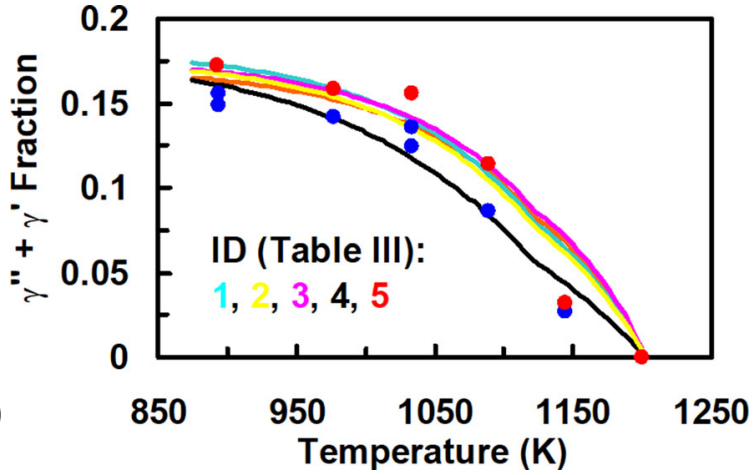

(b)

Fig. 14-Equilibrium solvus approach curves (SACs) used in the present work: (a) Comparison of example $\gamma^{\prime \prime}$ and $\gamma^{\prime}$ SACs with data points from the literature, as well as the overall $\gamma^{\prime \prime}+\gamma^{\prime}$ curve and (b) comparison of variations in the overall curve (Table III) and the present measurements.

hence undercooling) for the specific case of a matrix composition equivalent to that of a supersolvus-solution-treated material. For Eq. [1], values of the average enthalpy of transformation for $\gamma^{\prime}$ and $\gamma^{\prime \prime}$ were obtained respectively from the on-heating specific heat data for the ST sample (Figure 4(a)) and the average on-cooling data (Figure 4(b)). In the first instance, precipitation simulations for 718 showed that $\sim 4$ pct of the matrix transformed to $\gamma^{\prime}$ between $800 \mathrm{~K}$ and $900 \mathrm{~K}$. In combination with the measured heat release shown in Figure 4(b) over this range of temperature, $H_{\gamma^{\prime}}^{*}=115 \mathrm{~J} /$ $\mathrm{g}$ was obtained for the $\gamma^{\prime}$ formed in 718; this value is similar to those that pertain to $\gamma^{\prime}$ precipitation in the PM $\gamma-\gamma^{\prime}$ superalloys (Table I). A similar approach for the on-cooling behavior between $\sim 1073 \mathrm{~K}$ and $950 \mathrm{~K}$, during which it was estimated that $\sim 8$ pct. of $\gamma^{\prime \prime}$ and $\sim 2.3$ pct of $\gamma^{\prime}$ had formed and produced the measured amount of heat, resulted in an estimate of $184 \mathrm{~J} / \mathrm{g}$ for $H_{\gamma^{\prime \prime}}^{*}$, or a value approximately 50 pct. greater than that for $\gamma^{\prime}$. With these measurements and the corresponding solvus temperatures (Table II), $\Delta G^{*}(T)$ plots were obtained using Eq. [1] (Figure 16).

The corresponding $\Delta G^{*}(T)$ plots from Eq. [2] utilized the (assumed constant) precipitate compositions (Table II), equilibrium matrix compositions at a series of temperatures determined from the fitted SACs (cases 1 and 5 in Table III), and TFs of 1.05 (for the case of nucleation of $\gamma^{\prime \prime}$ controlled by $\mathrm{Nb}$ ) or 0.94 (for the case of nucleation of $\gamma^{\prime}$ controlled by Ti). For $\gamma^{\prime \prime}$, the resulting plot of $\Delta G^{*}(T)$ from the application of Eq. [2] (Figure 16(a)) showed excellent agreement with that derived from $H_{\gamma^{\prime \prime}}^{*}$ and the solvus temperature, except at low temperatures. Here, the more-formal Gibbs relation would be expected to show the proper leveling off of $\Delta G^{*}$ associated with the negligible change in equilibrium phase fractions/supersaturation at low temperatures in alloy 718 (Figure 15) coupled with the decrease in temperature per se. For $\gamma^{\prime}$, the agreement between the two $\Delta G^{*}(T)$ plots was only moderate, although the Gibbs relation did indeed show the expected peak and gradual drop with temperature. Although the Gibbs 
relation was used for all of the precipitation simulations in the present work (because it accounts for arbitrary matrix composition), the source of the difference in the two $\Delta G^{*}(T)$ plots for $\gamma^{\prime}$ warrants further investigation.

Table III. Fitting Coefficients for 718 Solvus Approach Curves

\begin{tabular}{llclcc}
\hline & \multicolumn{2}{c}{$\gamma^{\prime \prime}$} & & \multicolumn{2}{c}{$\gamma^{\prime}$} \\
\cline { 2 - 3 } \cline { 5 - 6 } ID & $4 \mathrm{C}_{\mathrm{o}}$ & $Q_{\mathrm{s}}(\mathrm{kJ} / \mathrm{mol})$ & & $4 \mathrm{C}_{\mathrm{o}}$ & $Q_{\mathrm{s}}(\mathrm{kJ} / \mathrm{mol})$ \\
\hline 1 & 0.130 & 120 & & 0.05 & 75 \\
2 & 0.125 & 120 & & 0.05 & 75 \\
3 & 0.125 & 150 & & 0.05 & 75 \\
4 & 0.125 & 75 & & 0.05 & 75 \\
5 & 0.120 & 150 & & 0.05 & 75 \\
\hline
\end{tabular}

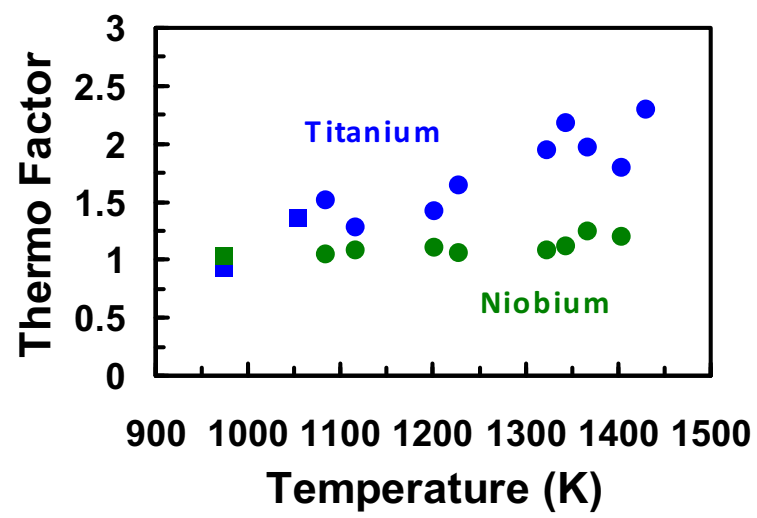

Fig. 15-CALPHAD predictions of the thermodynamic factors for $\mathrm{Nb}$ and $\mathrm{Ti}$ in nickel solid solutions for PM alloys ${ }^{[53]}$ (round points) and alloy 718 (square points).
2. Comparison of measurements and predictions

Predictions from the precipitation simulations were compared to metallographic observations and DSC measurements of $c-c_{b}$. Attention was focused on experiments performed at a cooling or heating rate of $5 \mathrm{~K} /$ min. The input material parameters are listed in Table II and the first line of each of Tables IV and V.

First, for cooling at $5 \mathrm{~K} / \mathrm{min}$ from a solution temperature above the $\delta$ solvus, precipitation simulations indicated that (i) substantial undercooling relative to both $T_{\gamma^{\prime \prime}}(\sim 1203 \mathrm{~K})$ and $T_{\gamma^{\prime}}(1123 \mathrm{~K})$ was required to nucleate precipitates (Figure 17(a)) and (ii) the evolution in size with decreasing temperature was comparable for $\gamma^{\prime \prime}$ and $\gamma^{\prime}$ (Figure 17(b)). Measurements for a sample quenched upon reaching $993 \mathrm{~K}$ (Figure 6(c), Section III-C) verified the accuracy of the predictions. Specifically, the simulated volume fraction of $\gamma^{\prime \prime}+\gamma^{\prime}$ at $993 \mathrm{~K}$ was 0.093 (Figure 17(a)), in excellent agreement with the measurement (0.094), and the predicted average diameter of the precipitates was $14.5 \mathrm{~nm}$ (Figure 17(b)). This value was somewhat greater than the measured CED (10.7 nm). Part of the difference was likely due to the shape of $\gamma^{\prime \prime}$. For an ellipsoidal precipitate having an aspect ratio (minor to major diameter) of $1: 1.5$ and a CED of $10.7 \mathrm{~nm}$, its major diameter would be $\sim 13 \mathrm{~nm}$, a value thought to be in good agreement with the prediction $(14.5 \mathrm{~nm})$ when considering adjustments for sectioning plane/stereological effects.

A comparison of the measured and simulated variation of $c-c_{b}$ with temperature for the on-cooling behavior (Figure 17(c)) exhibited similarity with regard to the overall shape of the curves. However, the DSC measurement showed a displacement of $\sim 25 \mathrm{~K}$ to lower temperatures relative to the simulation prediction. Such an apparent lag of the measurements may have resulted from the same source noted in the comparison of volume-fraction measurements and predictions for the two PM alloys.

Differences between measurements and predictions for heating of an ST 718 sample from room temperature at $5 \mathrm{~K} / \mathrm{min}$ appeared to be somewhat greater. In this instance, high-resolution SEM images for a sample

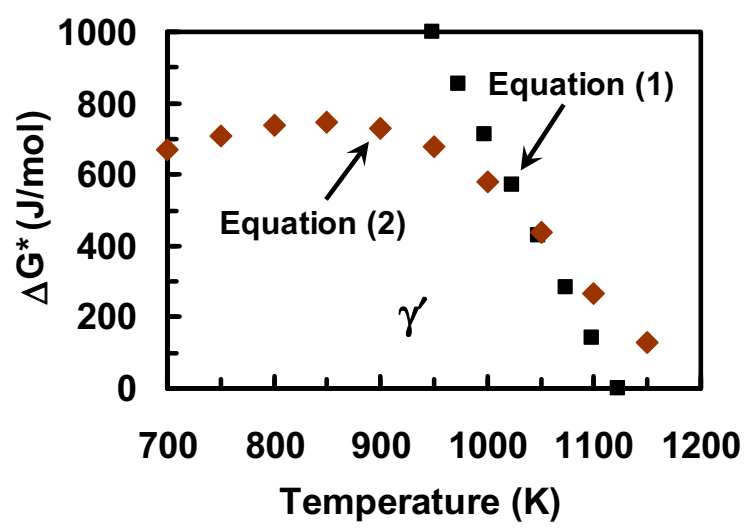

(b)

Fig. 16-Comparison of the temperature dependence of the bulk free energy of transformation/precipitation from a supersaturated solution corresponding to the overall composition of alloy 718 as predicted from Eqs. [1] or [2] for $(a) \gamma^{\prime \prime}$ or $(b) \gamma^{\prime}$. 
Table IV. Parameters/Predictions for 718 On-Cooling Sensitivity Analysis

\begin{tabular}{|c|c|c|c|c|c|c|c|}
\hline ID & $4 C_{o}\left(\gamma^{\prime \prime}\right)$ & $Q_{\mathrm{s}}\left(\gamma^{\prime \prime}\right)(\mathrm{kJ} / \mathrm{mol})$ & $\mathrm{TF}_{\mathrm{Nb}}\left(\gamma^{\prime \prime}\right)$ & Other Factor & Peak v/o $\gamma^{\prime \prime} / \gamma^{\prime}$ & Dia. $(\mathrm{nm}) \gamma^{\prime \prime} / \gamma^{\prime}$ & $T_{\mathrm{p}}\left(\gamma^{\prime \prime}\right)(\mathrm{K})$ \\
\hline $\mathrm{C} 1$ & 0.132 & 120 & 1.05 & - & $7.8 / 2.7$ & $13.9 / 14.4$ & 1050 \\
\hline $\mathrm{C} 2$ & 0.132 & 120 & 1.05 & $\Delta \mathrm{G}_{\mathrm{el}}=75 \mathrm{kJmol}$ & $6.6 / 3.3$ & $13.2 / 11.3$ & 1047 \\
\hline $\mathrm{C} 3$ & 0.132 & 120 & 1 & - & $9.1 / 0.6$ & $15.0 / 20.2$ & - \\
\hline $\mathrm{C} 4$ & 0.135 & 120 & 1.05 & - & $9.1 / 1.9$ & $14.9 / 17.5$ & - \\
\hline $\mathrm{C} 5$ & 0.125 & 150 & 1 & - & $8.9 / 0.04$ & $17.4 / 22.9$ & - \\
\hline C6 & 0.127 & 150 & 1.05 & - & $8.8 / 0.9$ & $16.8 / 20.7$ & 1065 \\
\hline $\mathrm{C} 7$ & 0.127 & 150 & 1.05 & $T_{\gamma^{\prime \prime}}=1193 \mathrm{~K}$ & $8.2 / 2.2$ & $14.8 / 16.5$ & 1056 \\
\hline $\mathrm{C} 8$ & 0.131 & 150 & 1.05 & - & $10.1 / 0.1$ & $18.6 / 24.2$ & - \\
\hline C9 & 0.135 & 150 & 1.05 & - & $11.0, \sim 0$ & $20.1 / 26.0$ & - \\
\hline
\end{tabular}

Parameters held fixed: $4 \mathrm{C}_{\mathrm{o}}\left(\gamma^{\prime}\right)=0.05, Q_{\mathrm{s}}\left(\gamma^{\prime}\right)=75 \mathrm{~kJ} / \mathrm{mol}, \mathrm{TF}_{\mathrm{Ti}}\left(\gamma^{\prime}\right)=0.94$.

Table V. Parameters/Predictions for 718 On-Heating Sensitivity Analysis

\begin{tabular}{lccccccc}
\hline ID & $4 \mathrm{C}_{\mathrm{o}}\left(\gamma^{\prime \prime}\right)$ & $Q_{\mathrm{s}}\left(\gamma^{\prime \prime}\right)(\mathrm{kJ} / \mathrm{mol})$ & $\mathrm{TF}_{\mathrm{Nb}}\left(\gamma^{\prime \prime}\right)$ & $\mathrm{TF}_{\mathrm{Ti}}\left(\gamma^{\prime \prime}\right)$ & Peak v/o $\gamma^{\prime \prime} / \gamma^{\prime}$ & $T_{\mathrm{v}}\left(\gamma^{\prime}\right)(\mathrm{K})$ & $T_{\mathrm{v}}\left(\gamma^{\prime \prime}\right)(\mathrm{K})$ \\
\hline H1 & 0.13 & 120 & 1.25 & 0.94 & $9.6 / 4.7$ & 888 \\
H2 & 0.13 & 120 & 1.3 & 0.94 & $9.5 / 4.8$ & 884 \\
H3 & 0.13 & 120 & 1.3 & 0.85 & $9.4 / 5.3$ & 868 \\
H4 & 0.12 & 150 & 1.1 & 0.94 & $9.3 / 4.4$ & 918 \\
H5 & 0.12 & 150 & 1.1 & 0.85 & $9.3 / 4.7$ & 894 \\
\hline
\end{tabular}

Parameters held fixed: $4 \mathrm{C}_{\mathrm{o}}\left(\gamma^{\prime}\right)=0.05, Q_{\mathrm{s}}\left(\gamma^{\prime}\right)=75 \mathrm{~kJ} / \mathrm{mol}$.

quenched at $1073 \mathrm{~K}$ (Figure 6(a)) revealed an area fraction of $\gamma^{\prime \prime}+\gamma^{\prime}$ of 0.072 with an average size of 6.5 $\mathrm{nm}$. By contrast, the precipitation simulations suggested the formation of $\gamma^{\prime \prime}$ with a volume fraction of $\sim 0.09$ and average size of $\sim 7 \mathrm{~nm}$ and $\gamma^{\prime}$ with an average size of 2 $\mathrm{nm}$ and volume fraction of $\sim 0.02$ (after some dissolution upon reaching $1073 \mathrm{~K}$ ) (Figures 18(a), (b)). Because of the very fine size of the $\gamma^{\prime}$ precipitates, it is likely they were not imaged during SEM examinations. Similarly, it is possible that some of the finer $\gamma^{\prime \prime}$ was also not detected. Thus, after adjustment for their oblate shape and accounting for the resolution in the SEM, the actual diameter and volume fraction of the $\gamma^{\prime \prime}$ precipitates were likely close to the values predicted.

With respect to the $c-c_{b}$ vs $T$ behavior for the $718 \mathrm{ST}$ on-heating trial, the measurement and prediction again showed similar shapes and heights of the two exothermic valleys (Figure 18(c)), but the locations were displaced. As before, part of the differences may be associated with limitations of DSC measurements. Errors in the simulations and the associated input data also cannot be disregarded as a source of the differences.

\section{Sensitivity analysis}

The possible influence of variations/errors in the thermodynamic input parameters on predictions of precipitation kinetics and specific-heat behavior was investigated via a number of additional simulations. Predicted phase fractions/average precipitate sizes and the temperatures at which $c-c_{b}$ curves exhibited a peak ( $\left.T_{\mathrm{p}}\right)$ or valley $\left(T_{\mathrm{v}}\right)$ were used to quantify the magnitude of the effects. For the sake of brevity, only a handful of these simulation results are presented and discussed here.

For the case of cooling from a super- $\delta$-solvus temperature at $5 \mathrm{~K} / \mathrm{min}$, for example, relatively-small (of the order of several percent) increases in $4 \mathrm{C}_{\mathrm{o}}\left(\gamma^{\prime \prime}\right)$ or decreases in $\mathrm{TF}_{\mathrm{Nb}}\left(\gamma^{\prime \prime}\right)$, either of which would increase $\Delta G^{*}\left(\gamma^{\prime \prime}\right)$ at a given temperature, tended to increase or decrease the predicted volume fractions of $\gamma^{\prime \prime}$ or $\gamma^{\prime}$, respectively, and increase the size of both types of precipitates (cases C1, C3, C4, Table IV). Similarly, an increase in the elastic misfit energy for $\gamma^{\prime \prime}$, i.e., from $\Delta \mathrm{G}_{\mathrm{el}}$ $=70$ (baseline in Table II) to $75 \mathrm{~kJ} / \mathrm{mol}$ tended to reduce its volume fraction and size while increasing the volume fraction of $\gamma^{\prime}$ (case C2 vs C1 in Table IV). This finding was likely due to complex interactions between nucleation and growth of the two phases. An increase in $Q_{\mathrm{s}}\left(\gamma^{\prime \prime}\right)$ from 120 to $150 \mathrm{~kJ} / \mathrm{mol}$ (cases C5 through C9 vs $\mathrm{C} 1$ through $\mathrm{C} 4)$ led to marginally larger volume fractions of the phases, but increased their predicted sizes as well. This trend probably resulted from the formation of high supersaturations at higher temperatures (enhancing nucleation during cooling) and higher diffusivity (enhancing growth) for the higher value of $Q_{\mathrm{s}}\left(\gamma^{\prime \prime}\right)$. The results in Table IV also revealed that increasing $\Delta \mathrm{G}_{\mathrm{el}}$ (which would retard nucleation of $\gamma^{\prime \prime}$ to a lower temperature) led to a marginal decrease $(\sim 3$ $\mathrm{K}$ ) in predicted $T_{\mathrm{p}}$ (cases $\mathrm{C} 1$ vs $\mathrm{C} 2$ ). On the other hand, $\mathrm{a} \sim 10 \mathrm{~K}$ decrease in the assumed $\gamma^{\prime \prime}$ solvus temperature $\left(T_{\gamma^{\prime \prime}}\right)$ resulted in a $10 \mathrm{~K}$ decrease in the predicted $T_{\mathrm{p}}$ (cases C6 vs C7).

Results for cases involving heating at a rate of $5 \mathrm{~K} /$ min (Table V) also highlighted the effect of thermodynamic parameters on simulation predictions. In these instances, higher values of $\mathrm{TF}_{\mathrm{Nb}}\left(\gamma^{\prime \prime}\right)$ of the order of 1.25 , relative to those pertaining to the higher- temperature, on-cooling cases (i.e., 1.05, Table IV), were required to produce reasonable predictions of $\gamma^{\prime \prime}$ size and volume fraction during heating. In this regard, an ambiguity/ discontinuity in the temperature dependence of 


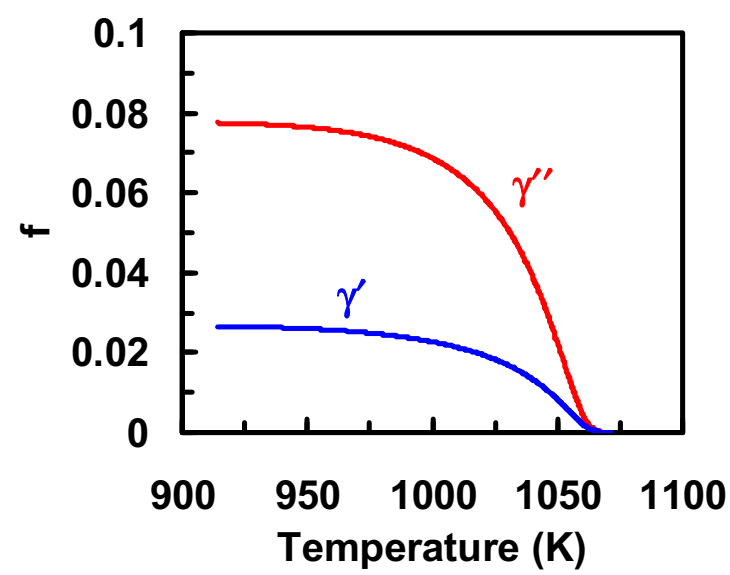

(a)

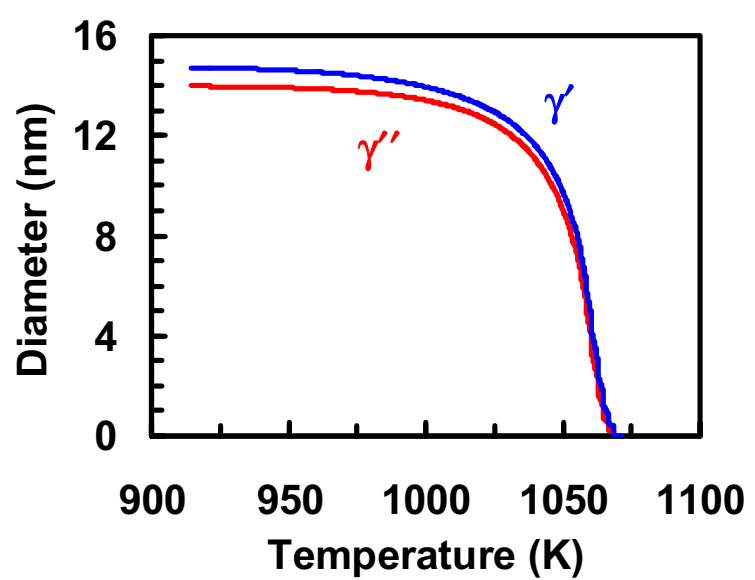

(b)

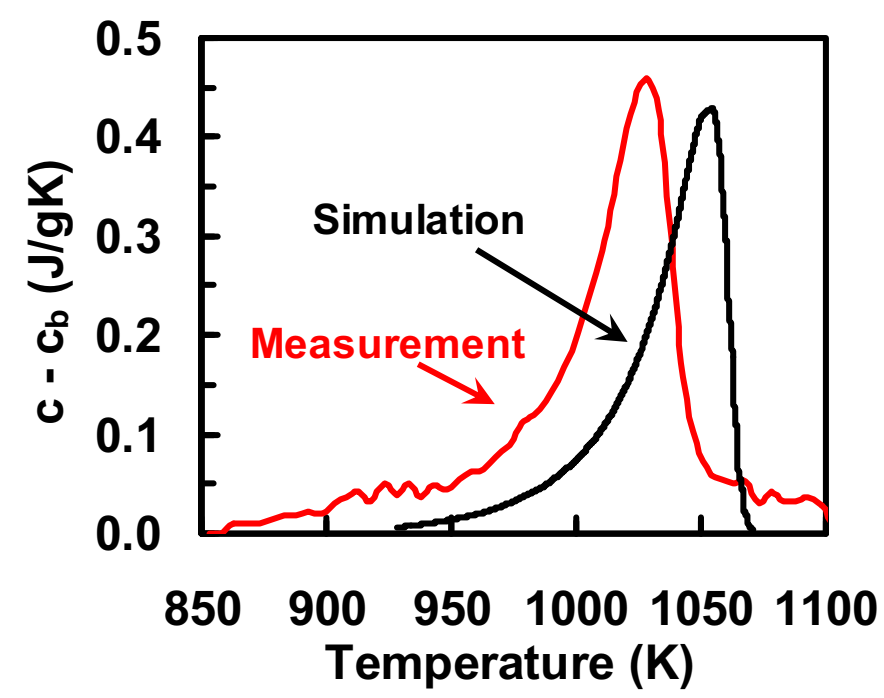

(c)

Fig. 17-Simulation predictions of the temperature dependence of precipitation kinetics in alloy 718 during cooling from above the $\delta$ solvus at a rate of $5 \mathrm{~K} / \mathrm{min}$ : (a) volume fractions of $\gamma^{\prime \prime}$ and $\gamma^{\prime},(b)$ average diameter of $\gamma^{\prime \prime}$ disks and $\gamma^{\prime}$ spheroids, and $(c) c-c_{b}$. In $(c)$, the simulation prediction is compared to a DSC measurement.

$\mathrm{TF}_{\mathrm{Nb}}\left(\gamma^{\prime \prime}\right)$ has also been suggested perhaps by the $\gamma^{\prime \prime}$ SAC at $T \sim 950 \mathrm{~K}$ reported by Saunders et al. ${ }^{[62]}$ Such uncertainty highlights the need for further work to enhance CALPHAD predictions of the free-energy curves that underlie $\mathrm{TF}_{\mathrm{Nb}}\left(\gamma^{\prime \prime}\right)$ predictions. Even with this ambiguity, however, the trends in Table $\mathrm{V}$ revealed that several combinations of $Q_{\mathrm{s}}\left(\gamma^{\prime \prime}\right)$ and $\mathrm{TF}_{\mathrm{Nb}}\left(\gamma^{\prime \prime}\right)$ can lead to similar predictions of the volume fractions of the phases. Results for cases $\mathrm{H} 2$ vs $\mathrm{H} 3$ and $\mathrm{H} 4$ vs $\mathrm{H} 5$ also indicated that a decrease in $\mathrm{TF}_{\mathrm{Ti}}\left(\gamma^{\prime}\right)$ from 0.94 to 0.85 leads to $\mathrm{a} \sim 15$ to $25 \mathrm{~K}$ decrease in the predicted temperature for the lower valley, $T_{\mathrm{v}}\left(\gamma^{\prime}\right)$, in $c$ - $c_{\mathrm{b}}$ curves. In a similar vein, an increase in $\mathrm{TF}_{\mathrm{Nb}}\left(\gamma^{\prime \prime}\right)$ from 1.25 to 1.3 was found to increase $T_{\mathrm{v}}\left(\gamma^{\prime \prime}\right)$ (for the upper-temperature valley dominated by $\gamma^{\prime \prime}$ precipitation) by $\sim 15 \mathrm{~K}$ (cases $\mathrm{H} 1$ vs $\mathrm{H} 2$ ). Both of these findings can be rationalized on the basis of the effect of TFs on the magnitude of the corresponding values of $\Delta G^{*}$ (Eq. [2]) and thus nucleation behavior.

\section{FUTURE OUTLOOK}

The present effort has demonstrated some of the strengths and weaknesses of experimental and numerical-modeling tools for investigating the kinetics of precipitation in nickel-base superalloys. Some areas of future research in this area include the following:

- It would be useful to develop factors to correct for the thermal inertia in DSC that appears to give rise to a lag in measurements of the heat generation/ specific heat that provides a signature of precipitation.

- Further analysis of DSC data may yield useful insight into the kinetics of precipitation/dissolution of very fine tertiary $\gamma^{\prime}$ in $\gamma-\gamma^{\prime}$ superalloys as well as the precipitation behavior that underlies the cooling-rate specification (between $993 \mathrm{~K}$ and $893 \mathrm{~K}$ ) that is often included in commercial heat treatments for alloy 718. Parallel simulation work to quantify 


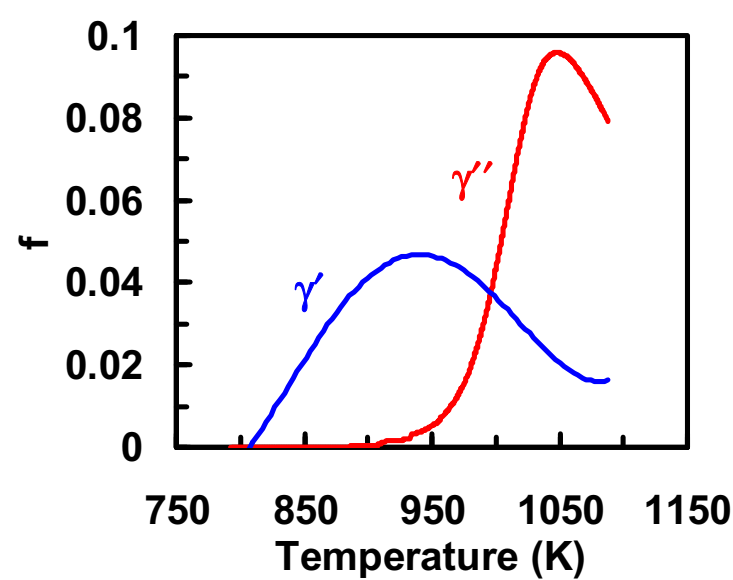

(a)

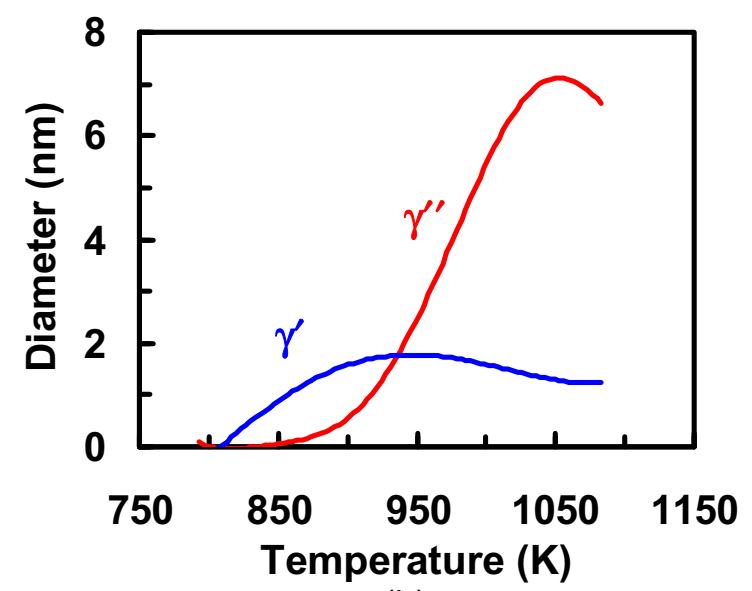

(b)

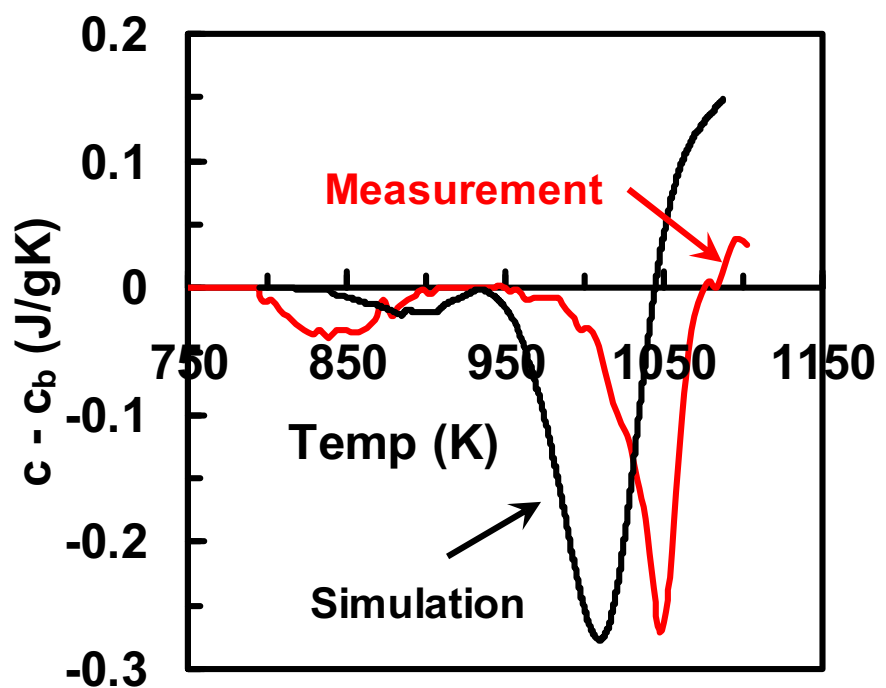

(c)

Fig. 18-Simulation predictions of the temperature dependence of precipitation kinetics in alloy 718 during the heating of an initially-solution-treated sample from room temperature at a rate of $5 \mathrm{~K} / \mathrm{min}$ : (a) volume fractions of $\gamma^{\prime \prime}$ and $\gamma^{\prime}$, (b) average diameter of $\gamma^{\prime \prime}$ disks and $\gamma^{\prime}$ spheroids, and $(c) c-c_{b}$. In (c), the simulation prediction is compared to a DSC measurement.

such lower-temperature precipitation phenomena would be useful as well to aid in the enhancement of DSC for such purposes.

- Further work to improve the thermodynamic database for alloy 718 as well for other (emerging) $\gamma-\gamma^{\prime}-\gamma^{\prime \prime}$ superalloys ${ }^{[63]}$ would be very beneficial to any effort in the area of modeling and simulation of these complex alloy systems.

\section{SUMMARY AND CONCLUSIONS}

Differential scanning calorimetry (DSC) was used to determine the dependence of specific heat on temperature for three nickel-base superalloys (IN-100, LSHR, and alloy 718) under on-cooling and on-heating conditions. The results from these experiments were compared to simulations of precipitation for each alloy. In addition, the simulations for 718 were facilitated by new measurements of the solvus-approach curve for $\gamma^{\prime \prime}$ $+\gamma^{\prime}$ and an analysis of thermodynamic factors for solutes that control the nucleation of the two phases. The following conclusions were drawn from this work:

(1) For powder-metallurgy (PM) $\gamma-\gamma^{\prime}$ superalloys such as IN-100 and LSHR, the variation of specific heat with temperature (less a baseline level representing the behavior under conditions that would pertain in the absence of phase transformation) can be used to obtain a semi-quantitative estimate of the kinetics of precipitation during cooling from supersolvus temperatures. The present observations and 
corresponding simulations suggest that the DSC results lag slightly the actual on-cooling behavior due to a thermal-inertia effect. Nevertheless, both the specific-heat and simulation results for the variation of volume fraction of $\gamma^{\prime}$ as a function of temperature are similar to those indicated by the equilibrium solvus-approach curve for temperatures below that at which the initial (secondary $\gamma^{\prime}$ ) precipitation burst occurs.

(2) Specific heat versus temperature plots for the on-cooling behavior of super- $\delta$-solvus solution treated samples of alloy 718 reveal that a much larger undercooling is required to initiate precipitation of $\gamma^{\prime \prime} / \gamma^{\prime}$ compared to that observed for $\gamma-\gamma^{\prime}$ superalloys. The shape of the 718 specific heat versus temperature curve for a given cooling rate mirrors predictions from precipitation simulations. As for the $\gamma-\gamma^{\prime}$ superalloys, however, the 718 on-cooling measurements also exhibit a lag of $\sim 25 \mathrm{~K}$ relative to model predictions. Such differences may be due to thermal inertia in the DSC method as well as uncertainty with regard to the input parameters for simulations of precipitation of 718 .

(3) On-heating specific heat versus temperature curves for alloy 718 exhibit a strong dependence on initial microstructural condition. Samples which have been super- $\delta$-solvus solution treated prior to on-heating DSC exhibit two exothermic valleys, a lower-temperature one associated with the precipitation of $\gamma^{\prime}$ and a higher temperature one associated with a competition of precipitation of $\gamma^{\prime \prime}$ and $\gamma^{\prime}$ and eventual dissolution of $\gamma^{\prime}$. These valleys, in conjunction with precipitation simulations, enable the determination of the enthalpy of formation of $\gamma^{\prime \prime}$ and $\gamma^{\prime}$ in 718. The present results have shown that the formation enthalpy for $\gamma^{\prime}$ in 718 is very similar to that for $\gamma^{\prime}$ in PM $\gamma-\gamma^{\prime}$ superalloys. By contrast, the enthalpy of formation of $\gamma^{\prime \prime}$ in 718 is approximately 50 pct. higher than that for $\gamma^{\prime}$.

(4) Model predictions of specific heat versus temperature for the on-heating behavior of solution-treated 718 samples are similar to observations, but the exothermic valleys are shifted relative to DSC observations. Part of the differences may be associated with errors in the input data that form an integral part of such predictions. One of the key sources of uncertainty lies with the temperature and composition dependence of the shape of free-energy curves and associated thermodynamic factors for the solutes that control nucleation.

(5) The on-heating specific-heat-versus-temperature behavior for 718 that has been aged or overaged prior to testing contrasts with that for the solution-treated condition. As expected, observations for these cases reveal no exothermic valleys (indicative of precipitation), but rather peaks due to the endothermic dissolution of $\gamma^{\prime} / \gamma^{\prime \prime}$, whose onset is retarded to higher temperatures by coarser precipitate sizes.

\section{ACKNOWLEDGMENTS}

Major portions of this work were conducted as part of the in-house research of the Air Force Research Laboratory's Materials and Manufacturing Directorate. Encouragement from and discussions with T.P. Gabb (NASA Glenn Research Center), B. Antolovich (ATI Specialty Materials), and M. Fahrmann (Haynes International) are very much appreciated.

\section{CONFLICT OF INTEREST}

On behalf of all authors, the corresponding author states that there is no conflict of interest.

\section{REFERENCES}

1. M.J. Donachie: Superalloys: Source Book, ASM International, Materials Park, OH, 1984.

2. R.C. Reed: The Superalloys: Fundamentals and Applications, Cambridge University Press, Cambridge, 2006.

3. T.M. Pollock and S. Tin: J. Propul. Power, 2006, vol. 22, pp. 361-74.

4. Y.C. Fayman: Mater. Sci. Eng., 1987, vol. 92, pp. 159-71.

5. J.W. Brooks and P.J. Bridges: in Superalloys 1988, S. Reichman, D.N. Duhl, G. Mauer, S. Antolovich, and C. Lund, eds., TMS, Warrendale, PA, 1988, pp. 33-42.

6. A. Oradei-Basile and J.F. Radovich: in Superalloys 718, 625, and Various Derivatives, E.A. Loria, ed., TMS, Warrendale, PA, 1991, pp. 325-35.

7. C.I. Garcia, A.K. Lis, E.A. Loria, and A.J. DeArdo: in Superalloys 1992, S.D. Antolovich, R.W. Stusrud, R.A. MacKay, D.L. Anton, T. Khan, R.D. Kissinger, and D.L. Klarstrom, eds., TMS, Warrendale, PA, 1992, pp. 527-36.

8. H. Chandler: Heat Treater's Guide: Practices and Procedures for Nonferrous Alloys, ASM International, Materials Park, OH, 1996.

9. C. Slama and G. Cizeron: Etude du Comportement Structural de l'Alliage NC $19 \mathrm{Fe} \mathrm{Nb}$ (Inconel 718), J. de Physique III, 1997, vol. 7, pp. 665-88.

10. A. Thomas, M. El-Wahabi, J.M. Cabrera, and J.M. Prado: $J$. Mater. Proc. Technol., 2006, vol. 177, pp. 469-72.

11. S.T. Wlodek, M. Kelly, D.A. Alden: in Superalloys 1996, R.D. Kissinger, D.J. Deye, D.L. Anton, A.D. Cetel, M.V. Nathal, T.M. Pollock, and D.A. Woodford, eds., TMS, Warrendale, PA, 1996, pp. 129-36.

12. D. U. Furrer: DEng Thesis, University of Ulm, Ulm, Germany, 1999.

13. D.U. Furrer and H.J. Fecht: Scripta Mater., 1999, vol. 40, pp. $1215-20$

14. R.J. Mitchell, M.C. Hardy, M. Preuss, and S. Tin: in Superalloys 2004, K.A. Green, T.M. Pollock, H. Harada, T.E. Howson, R.C. Reed, J.J. Schirra, and S. Walston, eds., TMS, Warrendale, PA, 2004, pp. 361-70.

15. H.-S. Liu, L. Zhang, X.-B. He, X.-H. Qu, Z. Li, and G.-Q. Zhang: Rare Met., 2013, vol. 32, pp. 560-63.

16. S.L. Semiatin, F. Zhang, J.S. Tiley, and D.U. Furrer: Mater. High Temp., 2016, vol. 33, pp. 301-09.

17. C. Papadaki, W. Li, and A.M. Korsunsky: Materials, 2018, vol. 11 (1528), pp. 1-10.

18. S.L. Semiatin, N.C. Levkulich, and J.S. Tiley: Metall. Mater. Trans. A, 2019, vol. 50A, pp. 5281-96.

19. A. Niang, B. Viguier, and J. Lacaze: Mater. Charact., 2010, vol. 61 , pp. $525-34$.

20. B.T. Alexandrov, J.C. Lippold, and S.J. Norton: U.S. Patent 7,909,505 B2, March 2011.

21. D.M. Collins, D.J. Crudden, E. Alabort, T. Connolley, and R.C. Reed: Acta Mater., 2015, vol. 94, pp. 244-56.

22. R.Y. Zhang, H.L. Qin, Z.N. Bi, J. Li, S. Paul, T.L. Lee, S.Y. Zhang, J. Zhang, and H.B. Dong: Metall. Mater. Trans. A, 2020, vol. 51A, pp. 574-85. 
23. J. Cormier, P. Gadaud, M. Czaplicki, R.Y. Zhang, H.B. Dong, T.M. Smith, F. Zhang, J.S. Tiley, and S.L. Semiatin: Metall. Mater. Trans. A, 2021, vol. 52A, pp. 500-11.

24. T.P. Gabb, D.G. Backman, D.Y. Wei, D.P. Mourer, D.U. Furrer, A. Garg, and D.L. Ellis: in Superalloys 2000, T.M. Pollock, R.D. Kissinger, R.R. Bowman, K.A. Green, M. McLean, S. Olson, and J.J. Schirra, eds., TMS, Warrendale, PA, 2000, pp. 405-14.

25. H.J. Jou, P.W. Voorhees, and G.B. Olson: in Superalloys 2004, K.A. Green, T.M. Pollock, H. Harada, T.E. Howson, R.C. Reed, J.J. Schirra, and S. Walston, eds., TMS, Warrendale, PA, 2004, pp. $877-86$.

26. G.B. Olson, H.J. Jou, J. Jung, J.T. Sebastian, A. Misra, I. Locci, and D. Hull: in Superalloys 2008, R.C. Reed, K.A. Green, P. Caron, T.P. Gabb, M.G. Fahrmann, E.S. Huron, and S.A. Woodard, eds., TMS, Warrendale, PA, 2008, pp. 923-32.

27. R. Radis, M. Schaffer, M. Albu, G. Kothleitner, P. Polt, and E. Kozeschnik: Acta Mater., 2009, vol. 57, pp. 5739-47.

28. B. Wang, F. Zhang, W. Cao, S. Chen, and S. Kou: Metall. Mater. Trans. A, 2015, vol. 46A, pp. 115-22.

29. S.L. Semiatin, S.-L. Kim, F. Zhang, and J.S. Tiley: Metall. Mater. Trans. A, 2015, vol. 46A, pp. 1715-30.

30. M.J. Anderson, F. Schulz, Y. Lu, H. Kitaguchi, P. Bowen, C. Argyrakis, and H.C. Basoalto: Acta Mater., 2020, vol. 161, pp. 81-100.

31. I.J. Moore, M.G. Burke, and E.J. Palmiere: Acta Mater., 2016, vol. 119, pp. 157-66.

32. R. Radis, G.A. Zickler, M. Stockinger, C. Sommitsch, and E. Kozeschnik: in Proc. $7^{\text {th }}$ International Sympsium on Superalloy 718 and Derivatives, E.A. Ott, J.R. Groh, A. Banik, I. Dempster, T.P. Gabb, R. Helmink, X. Liu, A. Mitchell, G.P. Sjoberg, and A. Wusatowski-Sarnek, eds. TMS, Warrendale, PA, 2010, pp. 569-78.

33. K. Wu, F. Zhang, S. Chen, W. Cao, and Y.A. Chang: in Superalloys 2008, R.C. Reed, K.A. Green, P. Caron, T.P. Gabb, M.G. Fahrmann, E.S. Huron, and S.A. Woodard, eds., TMS, Warrendale, PA, 2008, pp. 933-39.

34. D. Furrer, V. Venkatesh, F. Zhang, D. Gynther, T. Asare, D. Novikov, and S. Burlatsky: in Proc. $8^{\text {th }}$ International Sympsium on Superalloy 718 and Derivatives, E.A. Ott, A. Banik, X. Liu, I. Dempster, K. Heck, J. Andersson, J. Groh, T. Gabb, R. Helmink, and A. Wusatowska-Sarnek, eds. TMS, Warrendale, PA, 2014, pp. 81-94.

35. F. Zhang, W. Cao, C. Zhang, S. Chen, J. Zhu, and D. Lv: in Proceedings, 9th International Symposium on Superalloy 718 \& Derivatives: Energy, Aerospace, and Industrial Applications, E. Ott, ed., TMS, Pittsburgh, 2018, pp. 147-61.

36. A. Drexler, B. Oberwinkler, S. Primig, C. Turk, E. PovodenKaradeniz, A. Heinemann, W. Ecker, and M. Stockinger: Mater. Sci. Eng. A, 2018, vol. A723, pp. 314-23.

37. Z.K. Low, T. Chaise, D. Bardel, S. Cazottes, P. Chaudet, M. Perez, and D. Nelias: Acta Mater., 2018, vol. 156, pp. 31-42.

38. S.L. Semiatin, J.S. Tiley, F. Zhang, T.M. Smith, R.Y. Zhang, H.B. Dong, P. Gadaud, and J. Cormier: Metall. Mater. Trans. A, 2021, vol. 52A, pp. 483-99.

39. Y.H. Wen, J.P. Simmons, C. Shen, C. Woodward, and Y. Wang: Acta Mater., 2003, vol. 51, pp. 1123-32.

40. J.P. Simmons, Y. Wen, C. Shen, and Y. Wang: Mater. Sci. Eng. A, 2004, vol. A365, pp. 136-43.

41. M. Fleck, F. Schleifer, M. Holzinger, and U. Glatzel: Metall. Mater. Trans. A, 2018, vol. 49A, pp. 4146-57.
42. J. Gayda, T.P. Gabb, and P.T. Kantzos: in Superalloys 2004, K.A. Green, T.M. Pollock, H. Harada, T.E. Howson, R.C. Reed, J.J. Schirra, and S. Walston, eds., TMS, Warrendale, PA, 2004, pp. 323-30.

43. T.P. Gabb, J. Gayda, J. Telesman, and P. T. Kantzos: NASA Report TM-2005-213645, Glenn Research Center, Cleveland, OH, June 2005.

44. R. Larsen and T. Goerz: Report 5287, Thermophysical Properties Research Laboratory, West Lafayette, IN, January 2015.

45. R.E. Taylor, H. Groot, D.L. Taylor, and J. Ferrier: Report 2969, Thermophysical Properties Research Laboratory, West Lafayette, IN, May 2003.

46. S.L. Semiatin, J.M. Shank, A.R. Shiveley, W.M. Saurber, E.F. Gaussa, and A.L. Pilchak: Metall. Mater. Trans. A, 2014, vol. 45A, pp. 6231-51.

47. T. Alam, M. Chaturvedi, S.P. Ringer, and J.M. Cairney: Mater. Sci. Eng. A, 2010, vol. A257, pp. 7770-74.

48. A. Devaux, L. Naze, R. Molins, A. Pineau, A. Organista, J.Y. Guedou, J.F. Uginet, and P. Heritier: Mater. Sci. Eng. A, 2008, vol. A486, pp. 117-22.

49. D.P. Pishchur and V.A. Drebushchak: J. Therm. Analy. Calorim., 2016, vol. 124, pp. 951-58.

50. V. Koci, J. Fort, J. Madera, L. Scheinherrova, A. Trnik, and R. Cerny: IEEE Trans. Instrum. Meas., 2020, vol. 69, pp. 8178-86.

51. S.L. Semiatin, N.C. Levkulich, A.E. Saurber, D.W. Mahaffey, E.J. Payton, and O.N. Senkov: Metall. Mater. Trans. A, 2017, vol. 48A, pp. 5567-78.

52. R. Wagner and R. Kampmann: in Materials Science and Technology, vol. 5, P. Haasen, ed., VCH, Weinheim, Germany, 1991, pp. 213-303.

53. S.L. Semiatin, F. Zhang, R. Larsen, L.A. Chapman, and D.U. Furrer: Integr. Mater. Mfg. Innov., 2016, vol. 5 (3), pp. 1-20.

54. R. Przeliorz, F. Binczyk, P. Gradoin, M. Goral, and T. Mikuszewski: Archiv Foundry Eng., 2014, vol. 14 (3), pp. 67-70.

55. A.Sh. Agazhanov, D.A. Samoshkin, and Yu.M. Kozlovskii: Proc. 35th Siberian Thermophysical Sem., J. Physics Conf. Series, 2019, vol. 1382 (012175), pp. 1-5.

56. A. Olguin, M. Ortiz, C.H. Worner, O. Herrera, B.K. Kad, and P.M. Hazzledine: Phil. Mag. B, 2001, vol. 81, pp. 731-44.

57. W.F. Brown: Aerospace Structural Metals Handbook, CINDAS/ USAF CRDA Handbooks Operation, Purdue University, West Lafayette, IN, 1998, Codes 4101 and 4112.

58. B.F. Dyson: in Proc. Euromat 2001, Remini, Italy, 2001. (CD ROM).

59. E.J. Payton: PhD Dissertation, the Ohio State University, Columbus, OH USA, 2009.

60. Y.F. Han: M.S. Thesis, University of Manitoba, Winnipeg, Canada, 1981.

61. T.M. Smith, N.M. Senanayake, C.K. Sudbrack, P. Bonacuse, R.B. Rogers, P. Chao, and J. Carter: Mater. Charact., 2019, vol. 148, pp. 178-87.

62. N. Saunders, M. Fahrmann, and C.J. Small: in Superalloys 2000, K.A. Green, T.M. Pollock, R.D. Kissinger, eds., TMS, Warrendale, PA, 2000, pp. 803-11.

63. P.M. Mignanelli, N.G. Jones, M.C. Hardy, and H.J. Stone: Metall. Mater. Trans. A, 2018, vol. 49A, pp. 699-707.

Publisher's Note Springer Nature remains neutral with regard to jurisdictional claims in published maps and institutional affiliations. 